\title{
Preconditioning mesenchymal stromal cells with flagellin enhances the anti-inflammatory ability of their secretome against lipopolysaccharide-induced acute lung injury
}

\author{
RUI $\mathrm{LI}^{1 *}, \mathrm{YU} \mathrm{LI}^{2,3 *}$ and XIAOYAN DONG ${ }^{1}$ \\ ${ }^{1}$ Department of Pulmonary, Shanghai Children's Hospital, Shanghai Jiaotong University School of Medicine, \\ Shanghai 200062; ${ }^{2}$ Department of Plastic and Reconstructive Surgery, Shanghai Key Laboratory of Tissue Engineering, \\ Shanghai Ninth People's Hospital, Shanghai Jiao Tong University School of Medicine, Shanghai 200011, P.R. China; \\ ${ }^{3}$ Department of Hand, Plastic and Reconstructive Surgery, Burn Center-Hand and Plastic Surgery, \\ University of Heidelberg, BG Trauma Center Ludwigshafen, D-67071 Ludwigshafen, Germany
}

Received February 13, 2020; Accepted June 19, 2020

DOI: $10.3892 / \mathrm{mmr} .2020 .11380$

\begin{abstract}
Acute lung injury (ALI) is a complex condition frequently encountered in the clinical setting. The aim of the present study was to investigate the effect of conditioned media (CM) from human adipose-derived mesenchymal stromal cells (MSCs) activated by flagellin (F-CM), a Toll-like receptor 5 ligand, on inflammation-induced lung injury. In the in vitro study, RAW264.7 macrophages treated with F-CM had a higher proportion of cells with the M2 phenotype, lower expression of pro-inflammatory factors and stronger expression of anti-inflammatory genes compared with the CM from normal adipose-derived MSCs. Furthermore, in vivo experiments were performed in mice with ALI induced by intraperitoneal injection of lipopolysaccharide. F-CM significantly alleviated the lung exudation, inhibited inflammatory cell recruitment in lung tissues and decreased the concentration of inflammatory factors in the bronchoalveolar lavage fluid. These findings indicated that F-CM has superior anti-inflammation ability compared with $\mathrm{CM}$, and that it may represent a promising therapeutic approach to the treatment of inflammation-induced ALI.
\end{abstract}

Correspondence to: Professor Xiaoyan Dong, Department of Pulmonary, Shanghai Children's Hospital, Shanghai Jiaotong University School of Medicine, 355 Luding Road, Shanghai 200062, P.R. China

E-mail: dongxy@shchildren.com.cn

*Contributed equally

Key words: conditioned media, mesenchymal stromal cells, flagellin preconditioning, acute lung injury

\section{Introduction}

Acute lung injury (ALI)/acute respiratory distress syndrome (ARDS) is a critical condition characterized by neutrophil infiltration of the lungs, injury of alveolar epithelial cells and capillary endothelium, and protein-rich edema (1). ARDS is a severe lung condition developing from ALI, and epidemiological studies from Europe published in the past 20 years reported an ARDS incidence ranging from 5-8 cases/1,00,000 individuals (1). If not treated correctly or in a timely manner, ALI may lead to acute respiratory failure, including diffuse pulmonary interstitial and alveolar edema and severe hypoxic respiratory, insufficiency characterized by the progressive hypoxemia and respiratory distress $(2,3)$. Despite the development of promising new therapies to treat ALI during the past decade, including venovenous extracorporeal membrane oxygenation and lung-protective ventilation, the mortality of ALI remains high (40-50\%) (1). Therefore, it is important to investigate novel therapeutic methods for treating ALI.

Macrophages in lung tissue include alveolar macrophages, pulmonary interstitial macrophages and bronchial macrophages, and these are an important regulator of the local inflammatory microenvironment and immune response during ALI (4). When stimulated by external pathogenic factors, macrophages may be converted into a pro-inflammatory phenotype (M1) and release a large number of inflammatory mediators, such as tumor necrosis factor (TNF)- $\alpha$, interleukin (IL)-1 and IL-6, recruiting various immune cells and initiating an inflammatory cascade (5). However, with an increase in the level of pro-inflammatory cytokines, some macrophages will polarize toward an immunosuppressive phenotype (M2) and in turn inhibit the inflammatory reaction (6). Moreover, the disruption of the balance between M1 and M2 macrophages is considered to be one of the most important causes of the uncontrolled inflammatory cascade in ALI $(4,6)$.

Mesenchymal stromal cells (MSCs) are a type of fibroblast-like cells that have the ability of self-renewal and differentiation (7). MSCs have been detected in various 
tissues in the adult human body, such as the bone marrow, adipose tissue, umbilical cord blood and synovial fluid, from which they may be easily isolated (8). Although MSCs have a prominent ability to proliferate and differentiate, the fact that they die soon after being transplanted into the injured area suggests that their paracrine properties largely constitute the basis for their medical application $(9,10)$. Furthermore, the clinical use of MSCs has been limited by the long waiting times for cell preparation and the potential tumorigenicity safety concerns (11). To solve these aforementioned issues, some researchers have collected the bioactive factors secreted by MSCs in conditioned media (CM) as an alternative for MSCs and have reported positive results on improving cardiac function, skin wound repair and bone regeneration (11-13). In addition, the advantages of secure storage, transportation and administration also indicate CM may be a promising alternative for MSCs.

CM from MSCs is composed of a broad repertoire of bioactive factors, including cytokines, growth factors, microRNAs, proteasomes and exosomes. The wide range of anti-inflammatory cytokines secreted by MSCs, including transforming growth factor (TGF)- $\beta$, IL-1 receptor antagonist (IL-1Ra) and IL-10, suggests that CM can regulate the inflammatory process via a variety of mechanisms. For example, TGF- $\beta$ can induce M1 macrophage polarization towards the M2-like phenotype, inhibit the maturation of B cells and decrease the secretion of TNF- $\alpha$ and immunoglobulin E. Moreover, IL-1Ra can block IL-1 $\alpha /$ IL-1 $\beta$ signaling pathways, inhibit the antigen-presenting ability of dendritic cells and increase the number of immunosuppressive $\mathrm{T}$ cells, while IL-10 is a potent anti-inflammatory cytokine that can markedly inhibit the production of interferon (IFN) $-\gamma$, IL-2 and TNF- $\alpha$ (14-17).

Factors of the host microenvironment serve a key role in MSC-mediated immunomodulation (18). For instance, exposure of MSCs to inflammatory signals such as TNF- $\alpha$ and IL-1, is the basis of the in vivo MSC-mediated immunosuppression $(17,19)$. Given that the in vitro cell culture condition does not include inflammatory signals, preconditioning MSCs is a prerequisite for MSC-based therapy (20). MSCs derived from various tissues have been reported to express functional Toll-like receptors (TLRs), a type of single-pass transmembrane proteins $(21,22)$. TLR ligations can activate the immune defensive function of MSCs and alter their secretome profiles. For example, TLR4 ligands can activate the NF- $\kappa \mathrm{B}$ pathway in MSCs and induce MSCs to release a variety of molecules, including IL-6 and vascular endothelial growth factor (23). Therefore, priming MSCs with TLR ligations may be a promising method for enhancing their therapeutic effects.

Flagellin is a subunit protein of the flagellum, a whip-like appendage that enables bacterial motility, and it is a commonly used TLR5 ligand (24). The majority of previous studies have focused on preconditioning MSCs with TLR3 and TLR4 ligations $(22,23,25)$. While Linard et al (21) reported the superior anti-inflammatory effect of flagellin-activated MSCs in an irradiation-induced proctitis model compared with normal MSCs, whether MSCs preconditioned with flagellin are effective in other inflammation-related diseases and the mechanism underlying the beneficial effects of flagellin preconditioning on the MSCs remain elusive.
The aim of the present study was to investigate the effects of CM from normal adipose derived-MSCs (ADSCs) and CM from flagellin-activated ADSCs (F-CM) in a mouse model of ALI induced by intraperitoneal injection of lipopolysaccharide (LPS). Experiments were performed both in vitro and in vivo. The effects of CM and F-CM on the polarization and expression levels of inflammation-related factors were first investigated in RAW264.7 cells. Furthermore, CM and F-CM were injected into mice with LPS-induced lung injury to assess their anti-inflammatory activity in vivo. The current study also aimed to determine whether flagellin preconditioning can increase the beneficial effects of CM from ADSCs against LPS-induced ALI.

\section{Materials and methods}

Culture of human ADSCs. Human-ADSCs were purchased from the Type Culture Collection of the Chinese Academy of Sciences. The eight donors (men, 4; women, 4) were aged from 21-42 years old (the sex and age range of each sample were provided by the Type Culture Collection of the Chinese Academy of Sciences). The cells were centrifuged at $500 \mathrm{x} \mathrm{g}$ for $20 \mathrm{~min}$ at room temperature, and the cell pellet was diluted with D10 media which was composed of $89 \%$ DMEM-low glucose (DMEM-LG; Hyclone; Cytiva), 10\% FBS (Gibco; Thermo Fisher Scientific, Inc.) and $1 \%$ penicillin-streptomycin (Invitrogen; Thermo Fisher Scientific, Inc.). Then, cells were cultured in T-75 flasks (BD Biosciences) at $37^{\circ} \mathrm{C}$ in a humidified incubator containing $5 \% \mathrm{CO}_{2}$, and the culture media was changed twice a week. ADSCs were passaged when they were confluent, and the cells obtained at the end of the third passage were used for the experiments. ADSCs from different donors were separately cultured. ADSCs from all eight donors were used in all subsequent experiments, including the animal study.

Tri-lineage differentiation (osteocyte, chondrocyte and adipocyte) of the flagellin-activated ADSCs. For osteogenic and adipogenic differentiation, ADSCs were seeded on 6-well plates at the density of $1 \times 10^{5}$ cells/well. Osteogenic induction was performed using differentiation media consisting of DMEM-LG supplemented with $10 \% \mathrm{FBS}, 50 \mathrm{mg} / \mathrm{ml}$ of ascorbic acid, $10 \mathrm{mM} \beta$-glycerophosphate and $100 \mathrm{nM}$ dexamethasone (all Sigma-Aldrich; Merck KGaA). The media was changed every 3 days until day 21 .

Adipogenic studies were performed by culturing the cells in differentiation media containing $1 \mathrm{mM}$ dexamethasone, $50 \mathrm{mM}$ 3-isobutyl-1-methylxanthine and $10 \mathrm{mg} / \mathrm{ml}$ insulin (all Sigma-Aldrich; Merck KGaA).

For chondrogenesis, $1 \times 10^{5}$ cells were centrifuged at $500 \mathrm{x} \mathrm{g}$ in a polypropylene tube $(15 \mathrm{ml}$; BD Biosciences $)$ for $10 \mathrm{~min}$ at $4^{\circ} \mathrm{C}$. Aggregates were incubated in chondrogenic media consisting of DMEM supplemented with $10 \% \mathrm{FBS}$, $1 \%$ insulin-transferrin-selenium, $1 \mathrm{mM}$ sodium pyruvate and 50 mM L-proline (all Sigma-Aldrich; Merck KGaA).

After the differentiation processes were complete, cells were fixed in $4 \%$ paraformaldehyde for $30 \mathrm{~min}$ at $37^{\circ} \mathrm{C}$ and stained with Alizarin Red $\left(10 \mathrm{~min}\right.$ at $\left.37^{\circ} \mathrm{C}\right)$, Oil Red $\mathrm{O}\left(10 \mathrm{~min}\right.$ at $\left.37^{\circ} \mathrm{C}\right)$ and Toluidine Blue $\left(30 \mathrm{~min}\right.$ at $37^{\circ} \mathrm{C}$; all Beyotime Institute of Biotechnology), respectively. Then, 
cells were observed with a light microscope (Optiphot; Nikon Corporation) at a high-power magnification of x100.

Flow cytometry. After being incubated with D10 media containing flagellin (100 ng/ml; cat. no. P7388; Beyotime Institute of Biotechnology) at $37^{\circ} \mathrm{C}$ for $48 \mathrm{~h}$, ADSCs were harvested and suspended in PBS containing 4\% FBS. Non-specific detection of the Fc component of the CD antibodies were blocked with 5\% BSA (Beyotime Institute of Biotechnology) for $30 \mathrm{~min}$ at room temperature. Then, cells were incubated with fluorescence-conjugated antibodies directed against mouse anti-human CD31 (cat. no. 555446), CD45 (cat. no. 560178), CD73 (cat. no. 550257), CD90 (cat. no. 555593) and CD105 (cat. no. 562380; all from BD Biosciences; 1:20) for $30 \mathrm{~min}$ in the dark at $4^{\circ} \mathrm{C}$ After being washed three times with PBS, the stained cells were sorted using a FACSCalibur flow cytometer (BD Biosciences). The result was analyzed using BD FACStation software (version 6.1X; BD Biosciences).

Preparation of $C M$ and F-CM. When reaching 80-90\% confluency, the culture media was changed to a mixture of D10 media and flagellin $(100 \mathrm{ng} / \mathrm{ml})$. After $48 \mathrm{~h}$ incubation at $37^{\circ} \mathrm{C}$, flagellin-activated ADSCs were washed three times with warm PBS and re-supplemented with serum-free DMEM. After $48 \mathrm{~h}$, the CM was collected, filtered with a $0.2-\mu \mathrm{m}$ filter (EMD Millipore) and concentrated 50-fold using ultrafiltration units with a $3-k D a$ molecular weight cutoff (EMD Millipore) (26). The concentrated F-CM was stored at $-80^{\circ} \mathrm{C}$ before being used for the following experiments. The $\mathrm{CM}$ was prepared using the same method, except no flagellin was added.

Effect of serum deprivation on the viability of ADSCs. Normal ADSCs and ADSCs pretreated with flagellin $(100 \mathrm{ng} / \mathrm{ml})$ for $48 \mathrm{~h}$ at $37^{\circ} \mathrm{C}$ were cultured in 96-well plates at the density of $2 \times 10^{4}$ cells/well with serum-free culture media. After 0 , 24 and $48 \mathrm{~h}$, the serum-free culture media was removed and $200 \mu \mathrm{l}$ fresh culture media containing 10\% Cell Counting Kit-8 reagent (CCK-8; Dojindo Molecular Technologies, Inc.) were added to each well according to the manufacturer's instructions. After $2 \mathrm{~h}$ incubation at $37^{\circ} \mathrm{C}$, the absorbance was measured at $450 \mathrm{~nm}$.

Culture and treatment of RAW264.7 cells and THP-1 cells. RAW264.7 cells were purchased from the Type Culture Collection of the Chinese Academy of Sciences. Cells were cultured in 6-well plates at the density of $1 \times 10^{5}$ cells/well, and randomly divided into the control (20 $\mu \mathrm{l} / \mathrm{ml}$ PBS), LPS (1 $\mu \mathrm{g} / \mathrm{ml}$ LPS; Beyotime Institute of Biotechnology), CM $(1 \mu \mathrm{g} / \mathrm{ml} \mathrm{LPS}+20 \mu \mathrm{l} / \mathrm{ml} \mathrm{CM})$ and F-CM $(1 \mu \mathrm{g} / \mathrm{ml}$ LPS $+20 \mu \mathrm{l} / \mathrm{ml} \mathrm{F-CM)} \mathrm{groups.} \mathrm{The} \mathrm{cells} \mathrm{were} \mathrm{cultured} \mathrm{at} 37^{\circ} \mathrm{C}$ for $24 \mathrm{~h}$ and then tested.

THP-1 cells were purchased from the Type Culture Collection of the Chinese Academy of Sciences. Cells were cultured in RPMI-1640 medium (Hyclone; Cytiva) containing $10 \% \mathrm{FBS}, 100 \mathrm{U} / \mathrm{ml}$ penicillin and $100 \mu \mathrm{g} / \mathrm{ml}$ streptomycin (complete medium) and maintained at $37^{\circ} \mathrm{C}$ in a humidified, $5 \% \mathrm{CO}_{2}$ environment with medium changed every 2 days. Cells were cultured in 6-well plates at the density of $1 \times 10^{5}$ cells/well, and randomly divided into the control (20 $\mu \mathrm{l} / \mathrm{ml}$ PBS), LPS
$(1 \mu \mathrm{g} / \mathrm{ml} \mathrm{LPS}), \mathrm{CM}(1 \mu \mathrm{g} / \mathrm{ml} \mathrm{LPS}+20 \mu \mathrm{l} / \mathrm{ml} \mathrm{CM})$ and F-CM $(1 \mu \mathrm{g} / \mathrm{ml} \mathrm{LPS}+20 \mu \mathrm{l} / \mathrm{ml} \mathrm{F-CM})$ groups. The cells were cultured at $37^{\circ} \mathrm{C}$ for $24 \mathrm{~h}$ and then tested.

Reverse transcription-quantitative PCR (RT-qPCR). To extract RNA, $0.5 \mathrm{ml} \mathrm{TRIzol}{ }^{\circledR}$ reagent (Beyotime Institute of Biotechnology) was added in each well of cells after $24 \mathrm{~h}$ of culture or small pieces of the mouse lung tissue. mRNA dissolved in the TRIzol ${ }^{\circledR}$ reagent was isolated via centrifugation $(12,000 \mathrm{x} \mathrm{g} / \mathrm{min})$ at $4^{\circ} \mathrm{C}$ for $15 \mathrm{~min}$. cDNA was synthesized using a RT kit (cat. no. 4368813; Thermo Fisher Scientific, Inc.), Mouse-specific or human-specific primers with SYBR Green Master Mix (cat. no. 309155; Thermo Fisher Scientific, Inc.) used in the study are presented in Table I. The thermocycling conditions were as follows: Initial denaturation at $95^{\circ} \mathrm{C}$ for $5 \mathrm{~min}, 40$ cycles of denaturation at $95^{\circ} \mathrm{C}$ for $30 \mathrm{sec}$, annealing at $58^{\circ} \mathrm{C}$ for $30 \mathrm{sec}$ and extension at $72^{\circ} \mathrm{C}$ for $45 \mathrm{sec}$. The relative mRNA expression was calculated using the $2^{-\Delta \Delta \mathrm{Cq}}$ method (27). The GAPDH gene was used as the internal control.

ELISA. Commercial ELISA kits for human [C-C chemokine ligand 5 (CCL5; cat. no. DRN00B), IFN- $\gamma$ (cat. no. DIF50), IL-1 $\beta$ (cat. no. MLB00C), IL-1Ra (cat. no. DRA00B), IL-4 (cat. no. D4050), IL-6 (cat. no. D6050), IL-8 (cat. no. D8000C), IL-10 (cat. no. D1000B) and TGF- $\beta$ (cat. no. DB100B)] and mouse [TNF- $\alpha$ (cat. no. MTA00B), IL-1 (cat. no. MLB00C), IL-6 (cat. no. DY406), IL-10 (cat. no. M1000B) and monocyte chemoattractant protein (MCP)-1 (cat. no. MJE00B)] cytokines (all from R\&D Systems, Inc.) were used to determine the concentrations of inflammatory-associated factors in the bronchoalveolar lavage fluid (BALF) according to manufacturer's protocol.

Western blotting. To detect the expression of $\mathrm{NF}-\kappa \mathrm{B}$ pathway-related proteins, ADSCs treated with $100 \mathrm{ng} / \mathrm{ml}$ flagellin at $37^{\circ} \mathrm{C}$ for 0,30 and $120 \mathrm{~min}$ were harvested to obtain the cytoplasmic and nuclear proteins using a Keygen Kit (Nanjing Keygen Biotech Co., Ltd.) according to manufacturer's protocol. Total protein was quantified using the bicinchoninic acid Protein assay kit (Beyotime Institute of Biotechnology). The same amount of protein $(20 \mu \mathrm{g} /$ lane $)$ was placed into a $10 \%$ SDS-PAGE and transferred onto $0.22 \mu \mathrm{m}$ PVDF membranes (EMD Millipore). Then, the transferred membranes were blocked in 5\% BSA (Beyotime Institute of Biotechnology) at room temperature for $2 \mathrm{~h}$ and incubated with primary antibodies [p65, cat. no. AF5881, 1:1,000; $\mathrm{I} \kappa \mathrm{B} \alpha$, cat. no. AF5204, 1:1,000; phosphorylated (p)-I $\mathrm{B} \alpha$, cat. no. AF5851, 1:1,000; $\beta$-actin, cat. no. AF5006, 1:2,000; histone deacetylase 1 (HDAC1), cat. no. AF5180 1:2,000; all from Beyotime Institute of Biotechnology] overnight at $4^{\circ} \mathrm{C}$. $\beta$-actin and histone deacetylase 1 served as the internal controls. The membranes were washed with PBST containing $0.05 \%$ Tween (Shanghai Aladdin Bio-Chem Technology Co., Ltd.) three times followed by incubation with the corresponding horseradish peroxidase-conjugated secondary antibody (Beyotime Institute of Biotechnology) for $1 \mathrm{~h}$ at $37^{\circ} \mathrm{C}$. Protein bands were visualized using ECL reagents (Roche Diagnostics $\mathrm{GmbH}$ ) and then scanned with the Image Quant LAS4000 system (Cytiva). Protein 
Table I. Primer sequences $\left(5^{\prime} \rightarrow 3^{\prime}\right)$ for reverse transcription-quantitative PCR.

\begin{tabular}{|c|c|c|c|}
\hline Gene & Species & Forward primer & Reverse primer \\
\hline TNF- $\alpha$ & mice & СССТСАСАСТСАGATCATСТTCT & GCTACGACGTGGGCTACAG \\
\hline IL-6 & mice & GCC TTC CCT ACT TCA CAA & ACA ACTCTT TTC TCA TTT CCA C \\
\hline GAPDH & mice & GGAGCGAGATCCCTCCAAAAT & GGCTGTTGTCATACTTCTCATGG \\
\hline CD86 & mice & TGTTTCCGTGGAGACGCAAG & TTGAGCCTTTGTAAATGGGCA \\
\hline IL-10 & mice & GCTCTTACTGACTGGCATGAG & CGCAGCTCTAGGAGCATGTG \\
\hline IL-1 & mice & CTATGTCTTGCCCGTGGAG & CATCATCCCACGAGTCACA \\
\hline CD163 & mice & ATGGGTGGACACAGAATGGTT & CAGGAGCGTTAGTGACAGCAG \\
\hline TNF- $\alpha$ & human & CTCCCAGGTCCTCTTCAAGG & TTGATGGCAGAGAGGAGGTT \\
\hline IL-6 & human & CGGGAACGAAAGAGAAGCTC & ACAACAACAATCTGAGGTGC \\
\hline GAPDH & human & CCACRCCRCCACCTTTGAC & ACCCTGTTGTTGCTGTAGCCA \\
\hline CD86 & human & TGCTCATCTATACACGGTTACC3 & TGCATAACACCATCATACTCGA \\
\hline IL-10 & human & GCTGTCATCGATTTCTTCCC & TCAAACTCACTCATGGCTTTGT \\
\hline IL-1 & human & AATCTGTACCTGTCCTGCGTGTT & TGGGTAATTTTTGGGATCTACACTCT \\
\hline CD163 & human & CCAGTCCCAAACACTGTCCT & CACTCTCTATGCAGGCCACA \\
\hline $\operatorname{PPAR} \gamma$ & human & ACCAAAGTGCAATCAAAGTGG A & ATG AGG GAG TTG GAA GGC TCT \\
\hline ALP & human & ACTGGGGCCTGAGATACCC & TCGTGTTGCACTGGTTAAAGC \\
\hline RUNX2 & human & TCAACGATCTGAGATTTGTGGG & GGGGAGGATTTGTGAAGACGG \\
\hline SOX9 & human & AGCGAACGCACATCAAGAC & CTGTAGGCGATCTGTTGGGG \\
\hline COL2A1 & human & TGGACGATCAGGCGAAACC & GCTGCGGATGCTCTCAATCT \\
\hline Adiponectin & human & GGCTTTCCGGGAATCCAAGG & TGGGGATAGTAACGTAAGTCTCC \\
\hline
\end{tabular}

TNF, tumor necrosis factor; IL, interleukin; RUNX2, RUNX family transcription factor 2; PPAR $\gamma$, peroxisome proliferator activated receptor $\gamma ;$ ALP, alkaline phosphatase; COL2A1, collagen type II $\alpha 1$ chain.

expression levels were semi-quantified using Gel-Pro Analyzer software (version 4.0; Media Cybernetics, Inc.), with $\beta$-actin or HDAC1 as the loading control.

Animal model. All animal experiments were approved by the Animal Care and Use Committee of the Shanghai Children's Hospital. In total, 32 male BALB/c mice (age, 6-8 weeks; weight, 20-25 g) were purchased from Shanghai Lab Animal Research Center. Mice were maintained on a standard diet and water ad libitum (12 h light/dark cycle with humidity of $60 \pm 5 \%$ and temperature $22 \pm 3^{\circ} \mathrm{C}$ ). All mice were randomly divided into the control group $(n=8)$, the LPS group $(n=8 ;$ ALI mice received PBS), the CM group ( $n=8$; ALI mice received $\mathrm{CM}$ ) and the F-CM group (n=8; ALI mice received F-CM). PBS, CM or F-CM ( $5 \mu \mathrm{l} / \mathrm{g}$ of body mass of the animals) were injected into the tail vein of mice in the LPS, CM and F-CM groups once a day for 2 days before the experiment. ALI was induced via intraperitoneal injection of LPS $(20 \mu \mathrm{l} / \mathrm{g})(28,29)$. Then, $24 \mathrm{~h}$ after injection, mice were euthanized with $0.9 \%$ saline containing sodium pentobarbital $(50 \mathrm{mg} / \mathrm{ml})$ via intraperitoneal injection at dose of $250 \mathrm{mg} / \mathrm{kg}$ of body mass of the animals.

Cell counting and protein content in BALF. Each mouse was euthanized with sodium pentobarbital via intraperitoneal injection. Both lungs of each mouse were lavaged three times via a tracheal cannula with $0.5 \mathrm{ml} \mathrm{PBS}$ at $4^{\circ} \mathrm{C}$ to obtain BALF. BALF was centrifuged $\left(300 \mathrm{x} \mathrm{g} ; 10 \mathrm{~min} ; 4^{\circ} \mathrm{C}\right)$ and the protein content of the BALF supernatant was determined using the
Braford method (Beyotime Institute of Biotechnology), according to the manufacturer's instructions. The cell pellet was washed with red blood cell lysis solution (Beyotime Institute of Biotechnology) at $37^{\circ} \mathrm{C}$ for $1 \mathrm{~min}$, centrifuged at $300 \mathrm{x} \mathrm{g}$ at room temperature for $10 \mathrm{~min}$ and resuspended in $200 \mu \mathrm{l}$ PBS. The total cell count was determined using a hemocytometer and differential cell count was measured using Wright-Giemsa staining (incubated with Wright-Giemsa for $1 \mathrm{~min}$ at room temperature; Beyotime Institute of Biotechnology). Macrophages and neutrophils were quantified by counting 200 cells per slide at x400 magnification using light microscope.

Hematoxylin and eosin $(H \& E)$ staining. Lung tissue was washed three times with PBS and immersed in 4\% paraformaldehyde (Beyotime Institute of Biotechnology) overnight at room temperature. Then, lung tissue was dehydrated with an increasing gradient concentration of ethanol (50, 70, 80, 90 and 100\%) and embedded in paraffin (Beyotime Institute of Biotechnology). Tissue slices with thickness of $4 \mu \mathrm{m}$ were attached to the slides coated with polylysine (Beyotime Institute of Biotechnology) and were incubated overnight at $60^{\circ} \mathrm{C}$. Then, the slices were immersed in hematoxylin purple solution (Beyotime Institute of Biotechnology) at $37^{\circ} \mathrm{C}$ for $5 \mathrm{~min}$, washed three times with deionized water, washed in $1 \%$ hydrochloric acid alcohol (Shanghai Aladdin Bio-Chem Technology Co., Ltd.) for $5 \mathrm{sec}$ and rinsed in deionized water for $10 \mathrm{~min}$. Slices were then immersed in eosin dyeing solution at $37^{\circ} \mathrm{C}$ (Beyotime Institute of Biotechnology) for 
$30 \mathrm{sec}$, in $95 \%$ ethanol for $2 \mathrm{~min}$, in $100 \%$ ethanol for $2 \mathrm{~min}$, in $100 \%$ xylene (Beyotime Institute of Biotechnology) for $5 \mathrm{~min}$, and in the mixture of xylene and ethanol (1:1), respectively.

Lung injury was evaluated by two blinded observers according to a previous method by Smith et al (30). The parameters, lung edema, alveolar and interstitial inflammation, alveolar and interstitial hemorrhage, atelectasis and hyaline membrane formation, were scored as followed: i) No injury $=$ score of 0 ; ii) injury in $25 \%$ of the field $=$ score of 1 ; iii) injury in $50 \%$ of the field $=$ score of 2 ; iv) injury in $75 \%$ of the field $=$ score of 3 ; and $v$ ) injury throughout the field $=$ score of 4 . The lung injury score was the sum of these five criteria. In total, 12 random light microscopic (magnification, $\mathrm{x} 400$ ) fields from each slide were imaged and the injury area was calculated using ImageJ 1.8 software (National Institutes of Health).

Lung wet/dry weight ratio. After the mice were euthanized, their lungs were excised, rinsed briefly in PBS, blotted dry and weighed to obtain the wet weight. Then, the lungs were placed in an oven at $80^{\circ} \mathrm{C}$ for $48 \mathrm{~h}$ to obtain the dry weight. The ratio of wet lung weight to dry lung weight was calculated.

Statistical analysis. Data are presented as the mean \pm standard deviation. Differences between or among groups were examined for statistical significance using a unpaired Student's t-test, one-way ANOVA with Tukey's post hoc or Kruskal-Wallis with Dunn's post hoc test using GraphPad Prism 6 (GraphPad Software, Inc.). $\mathrm{P}<0.05$ was considered to indicate a statistically significant difference. Experiments were repeated $\geq 8$ times.

\section{Results}

Characterization of ADSCs with flagellin preconditioning. Flagellin-activated ADSCs were positive for MSC markers, including CD73 (Fig. 1C), CD90 (Fig. 1D) and CD105 (Fig. 1E), but negative for the endothelial cell marker CD31 (Fig. 1A) and the hematopoietic cell marker CD45 (Fig. 1B). Moreover, flagellin-activated ADSCs maintained a fibroblast-like morphology (Fig. 1F). The osteogenic (Fig. 1G), adipogenic (Fig. 1H) and chondrogenic (Fig. 1I) differentiation of flagellin-activated ADSCs was identified using Alizarin Red S, Oil Red O and Toluidine Blue staining, respectively.

The mRNA expression levels of the osteogenic genes alkaline phosphatase $(2.77 \pm 0.46)$ and RUNX family transcription factor $2(3.83 \pm 0.48)$, the adipogenic genes adiponectin $(66.74 \pm 4.43)$ and peroxisome proliferator activated receptor $\gamma$ $(10.77 \pm 1.29)$ and the chondrogenic genes collagen type II $\alpha$ 1 chain $(3.97 \pm 0.91)$ and SOX9 (2.15 \pm 0.17$)$, were significantly increased after differentiation induction compared with the control (Fig. 1J-O).

Effect of serum deprivation on the viability of ADSCs. Both the viability of ADSCs ( $0 \mathrm{~h}, 1.059 ; 24 \mathrm{~h}, 0.84$; and $48 \mathrm{~h}, 0.62)$ and flagellin-activated ADSCs $(0 \mathrm{~h}, 1.013 ; 24 \mathrm{~h}, 0.89$; and $48 \mathrm{~h}, 0.74$ ) decreased over time (Fig. 1P). However, ADSCs retained $59 \%$ viability and flagellin-activated ADSCs retained $73 \%$ viability. No differences were found between ADSCs and flagellin-activated ADSCs groups after $24 \mathrm{~h}$ incubation.
At $48 \mathrm{~h}$, the optical density value of the flagellin-activated ADSCs group was significantly higher compared with the ADSCs group.

Immunomodulatory effects of F-CM on murine macrophages. The immunomodulatory effect of F-CM was investigated in vitro using RAW264.7 cells. The effects of F-CM on the expression of the M1 marker C-C chemokine receptor (CCR)7 and the M2 marker CD206 were evaluated with flow cytometry. After a 48-h incubation, F-CM groups exhibited a significantly lower percentage of CCR7-positive cells $(67.66 \pm 5.32 \%$; Fig, $2 \mathrm{~B})$, but a significantly higher percentage of CD206-positive cells (41.75 $44.48 \%$; Fig. 2C) compared with

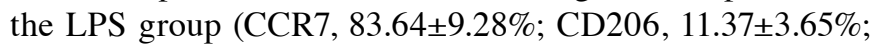
Fig. 2). The CM group had a significantly higher percentage of CD206-positive cells $(22.79 \pm 5.87 \%)$ compared with the LPS group, but the percentage of CCR7-positive cells of the CM group $(80.26 \pm 8.96 \%)$ was not significantly different compared with the LPS group (Fig. 2).

The effects of F-CM on the expression of inflammation-related genes were investigated using PCR analysis. Compared with PBS (the control group), LPS significantly increased the expression levels of pro-inflammatory factors, including TNF- $\alpha$ (7.11 \pm 0.91 ; Fig. 3A), IL-1 (5.60 \pm 0.83 ; Fig. 3B) and IL-6 (3.77 \pm 0.60 ; Fig. 3C), the expression of the M1 macrophage marker CD86 (4.58 \pm 0.56 ; Fig. 3E) and even

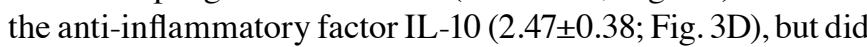
not affect the expression of the M2 macrophage marker CD163 $(0.99 \pm 0.32$; Fig. 3F). Furthermore, CM and F-CM significantly inhibited the expression levels of pro-inflammatory TNF- $\alpha$ (CM, 3.73 \pm 0.67 ; F-CM, 2.14 \pm 0.61 ; Fig. 3A), IL-1 (CM, 3.48 \pm 0.80 ; F-CM, 3.22 \pm 0.95 ; Fig. 3B), IL-6 (CM, 2.70 \pm 0.68 ; F-CM, 1.65 \pm 0.35 ; Fig. 3C) and CD86 (CM, 2.55 \pm 0.38 ; F-CM, $1.81 \pm 0.42$; Fig. $3 \mathrm{E})$, but further enhanced the expression levels

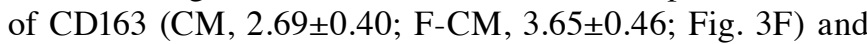

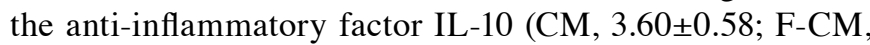
4.42 \pm 0.68 ; Fig. 3D), compared with LPS.

Immunomodulatory effects of F-CM on human macrophages. The immunomodulatory effect of F-CM was also investigated in THP-1 cells (Fig. 4). Consistent with the aforementioned results, LPS significantly increased the percentage of CCR7-positive cells $(79.23 \pm 7.40 \%)$, but CM and F-CM significantly decreased the percentage of CCR7-positive cells

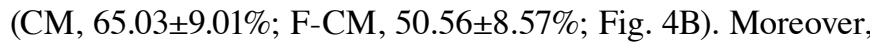
$\mathrm{CM}$ and F-CM groups also had a significantly higher ratio of

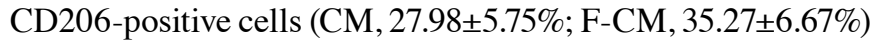
compared with the LPS group (6.19 $\pm 2.40 \%$; Fig. 4C).

The effects of F-CM on the expression levels of inflammation-related genes were examined using PCR analysis. Compared with PBS (the control group), LPS significantly increased the expression levels of TNF- $\alpha(4.81 \pm 0.54)$,

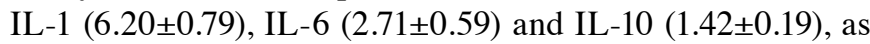
well as the expression of the M1 macrophage marker CD86 (3.28 \pm 0.59$)$, but markedly decreased the expression of the

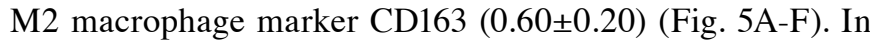
addition, CM and F-CM significantly inhibited the expression levels of TNF- $\alpha$ (CM, 2.80 \pm 0.79 ; F-CM, 1.98 \pm 0.45$)$, IL-1 (CM,

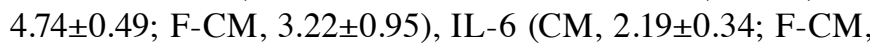

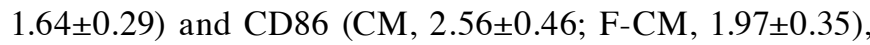



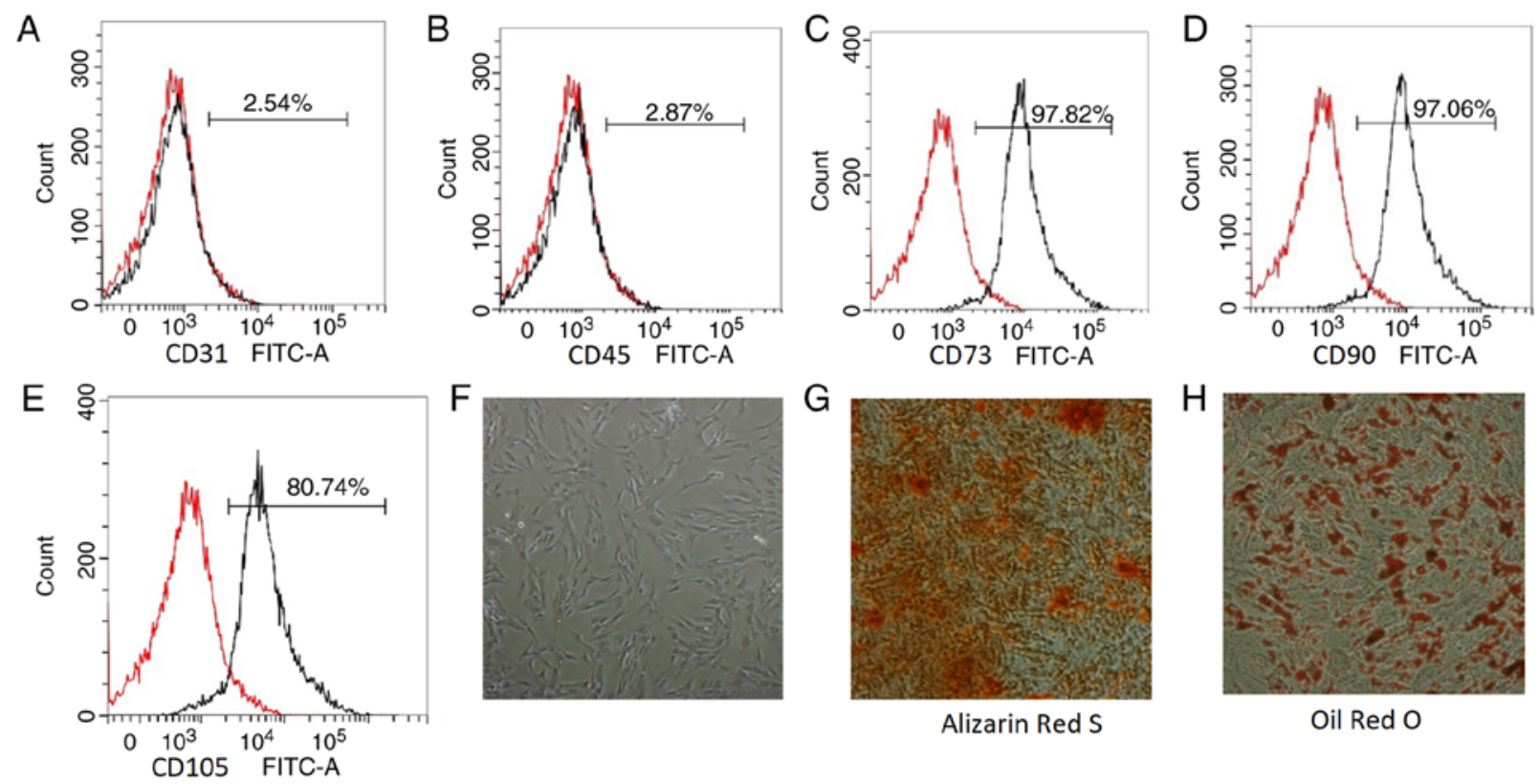
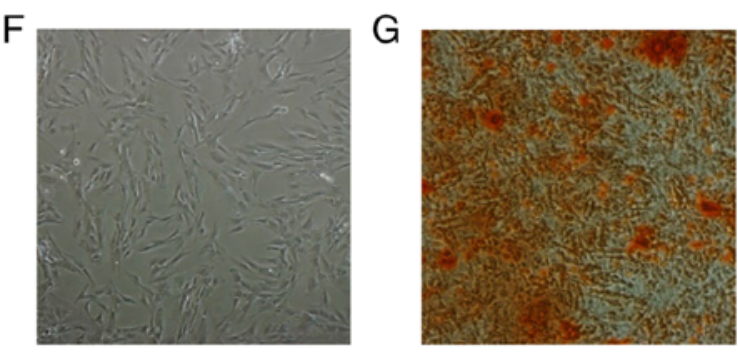

Alizarin Red S

$\mathrm{K}$

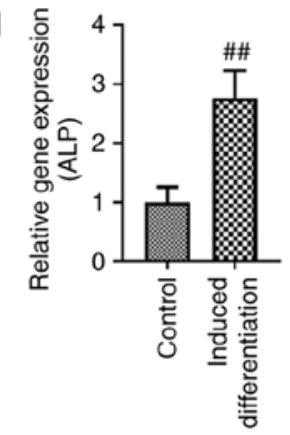

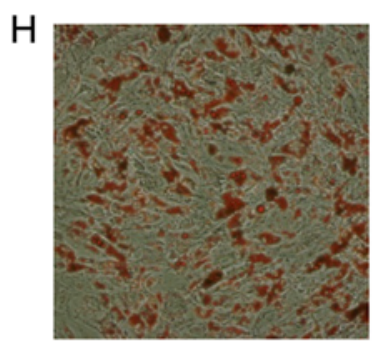

Oil Red O

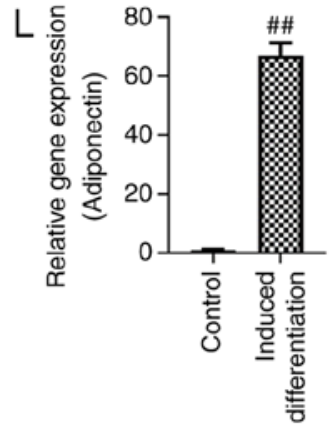

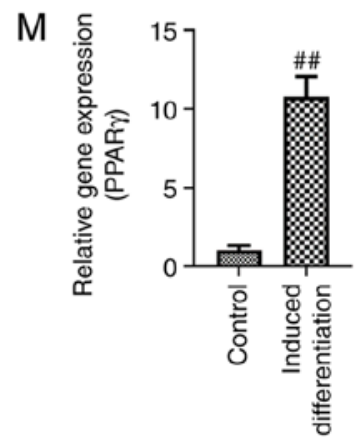
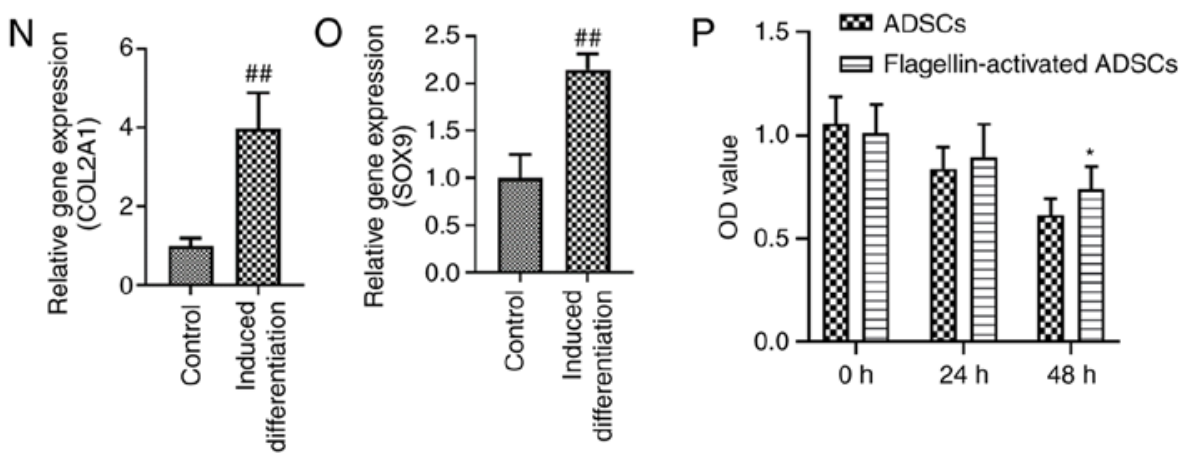

Figure 1. Characterization of ADSCs with flagellin preconditioning and effects of serum deprivation on the viability of ADSCs. Flow cytometric analyses demonstrated that ADSCs in passage 3 were negative for (A) CD31 and (B) CD45, but positive for (C) CD73, (D) CD90 and (E) CD105. (F) Flagellin-activated ADSCs maintained a fibroblast-like morphology. Magnification, x100. (G) Osteogenic, (H) adipogenic and (I) chondrogenic differentiation of flagellin-activated ADSCs was assessed using Alizarin Red S, Oil Red O and Toluidine Blue staining, respectively. Magnification, x100. Expression levels of (J) ALP and (K) RUNX2 are used to investigate osteogenic differentiation. Expression levels of (L) adiponectin and (M) PPAR $\gamma$ are used to investigate adipogenic differentiation. Expression levels of (N) COL2A1 and (O) SOX9 were used to investigate chondrogenic differentiation. (P) Cell Counting Kit-8 was used to detect the viability of ADSC and flagellin-activated ADSCs cultured in serum-free media. Differences between groups were examined for statistical significance using Student's t-test. " $\mathrm{P}<0.05$ vs. ADSCs group; ${ }^{\# \#} \mathrm{P}<0.01$ vs. control group. RUNX2, RUNX family transcription factor 2 ; PPAR $\gamma$, peroxisome proliferator activated receptor $\gamma$; ALP, alkaline phosphatase; COL2A1, collagen type II $\alpha 1$ chain; ADSC, adipose derived- mesenchymal stromal cells; OD, optical density.

but enhanced the expression levels of CD163 (CM, 2.70 \pm 0.41 F-CM, 3.82 \pm 0.43 ; Fig. 5E) and the anti-inflammatory factor

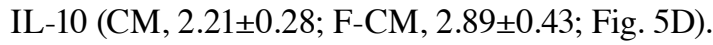

Changes of inflammatory cytokines in CM from flagellin-activated ADSCs. The levels of CCL5, IFN- $\gamma$, IL-1 $\beta$, IL-1Ra, IL-4, IL-6, IL-8, IL-10 and TGF- $\beta$ were assessed using ELISA (Fig. 6A). No significant differences in the levels of CCL5
(CM, 36.75 $\pm 10.87 \mathrm{pg} / \mathrm{ml}$; F-CM, 35.25 $\pm 10.50 \mathrm{pg} / \mathrm{ml}$ ), IFN- $\gamma$ (CM, 150.3 $\pm 22.60 \mathrm{pg} / \mathrm{ml}$; F-CM, $146.8 \pm 23.94 \mathrm{pg} / \mathrm{ml})$, IL-1 $\beta$ (CM, $58.75 \pm 6.85 \mathrm{pg} / \mathrm{ml}$; F-CM, $45.50 \pm 13.48 \mathrm{pg} / \mathrm{ml}$ ), IL-1Ra (CM, 45.50 $\pm 13.67 \mathrm{pg} / \mathrm{ml}$; F-CM, 59.25 $\pm 18.48 \mathrm{pg} / \mathrm{ml}$ ), IL-4 (CM, $19.25 \pm 12.61 \mathrm{pg} / \mathrm{ml}$; F-CM, $19.75 \pm 10.24 \mathrm{pg} / \mathrm{ml}$ ) or IL-10 $(\mathrm{CM}, 41.45 \pm 18.30 \mathrm{pg} / \mathrm{ml} ; \mathrm{F}-\mathrm{CM}, 34.38 \pm 15.64 \mathrm{pg} / \mathrm{ml}$ ) were observed between the two types of CM. However, flagellin preconditioning significantly increased the levels of IL-6 

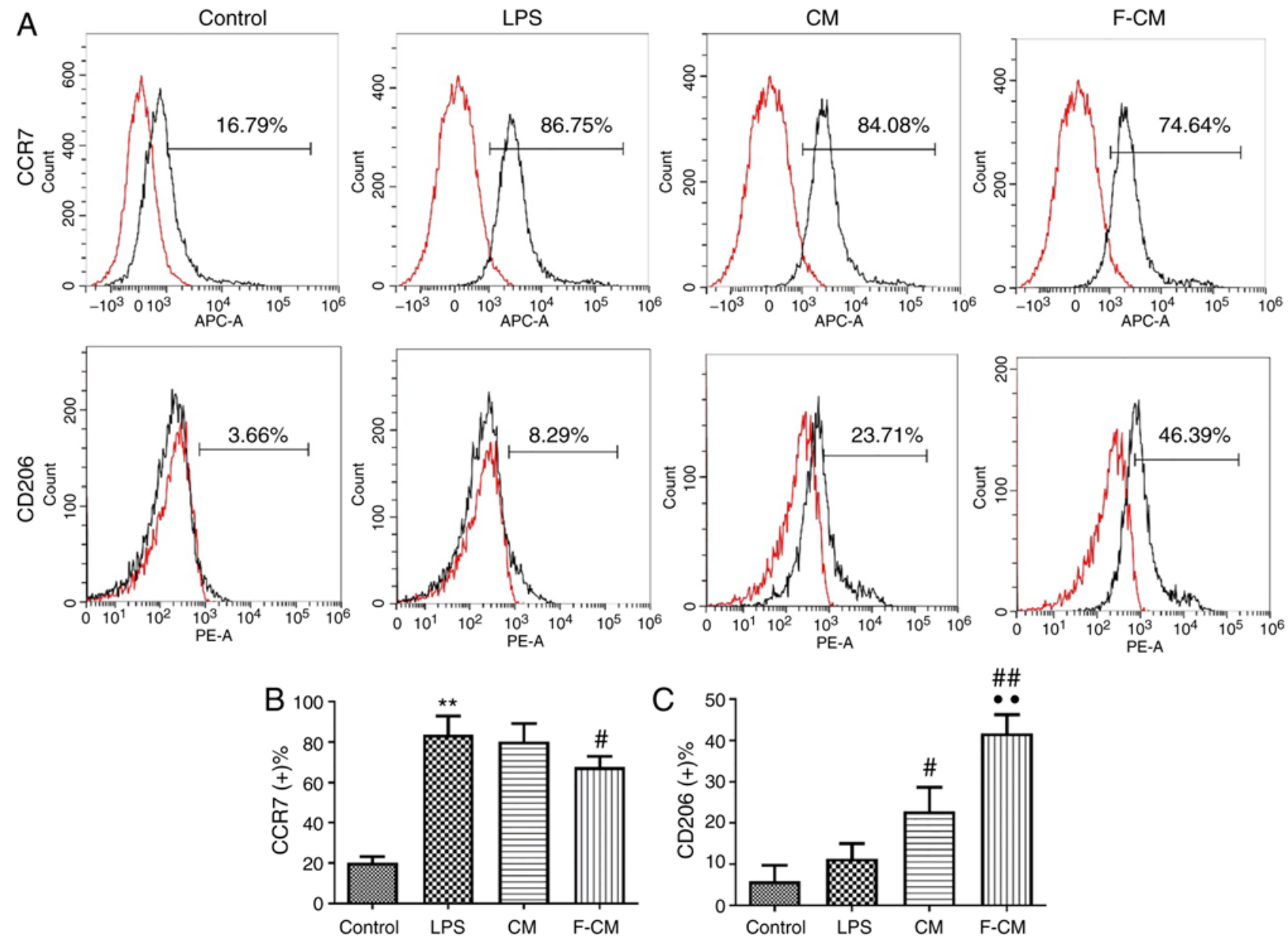

Figure 2. Effects of F-CM on surface markers of murine macrophages. (A) Flow cytometric analysis of (B) CCR7 positive cells represent M1 macrophages and (C) CD206 positive cells represent M2 macrophages. Differences among groups were examined for statistical significance using ANOVA. ${ }^{* *} \mathrm{P}<0.01$ vs. control group; ${ }^{\#} \mathrm{P}<0.05$ and ${ }^{\# \#} \mathrm{P}<0.01$ vs. LPS group; ${ }^{\bullet} \mathrm{P}<0.01$ vs. CM group. $\mathrm{CM}$, conditioned medium; F-CM, flagellin-conditioned medium; LPS, lipopolysaccharide; CCR, C-C chemokine receptor.

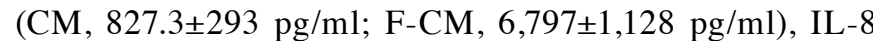
(CM, 6,786 $2,182 \mathrm{pg} / \mathrm{ml} ; \mathrm{F}-\mathrm{CM}, 40,605 \pm 7,560 \mathrm{pg} / \mathrm{ml})$ and TGF- $\beta$ (CM, $130.3 \pm 31.19$ pg/ml; F-CM, 436.8 \pm 105.5 pg/ml) compared with CM.

Effects of flagellin on $N F-\kappa B$ signaling pathway in ADSCs. Western blotting results indicated that the expression level of p65 protein, a subunit of NF- $\kappa \mathrm{B}$, was significantly decreased in the cytoplasm (30 $\mathrm{min}, 0.80 \pm 0.08 ; 120 \mathrm{~min}, 0.56 \pm 0.17$ ), while its presence in the nucleus increased significantly after ADSCs were treated with flagellin (30 min, 1.18 \pm 0.13 ; $120 \mathrm{~min}, 2.05 \pm 0.19$; Fig. $6 \mathrm{~B}$ and C). Moreover, p-I $\kappa \mathrm{B} \alpha$ expression (30 $\mathrm{min}, 1.38 \pm 0.12 ; 120 \mathrm{~min}, 2.29 \pm 0.25$ ) was increased, while total $\mathrm{I} \kappa \mathrm{B} \alpha$ expression decreased in the cytoplasm (30 $\mathrm{min}, 0.94 \pm 0.07 ; 120 \mathrm{~min}, 0.77 \pm 0.14$; Fig. $6 \mathrm{~B}$ and $\mathrm{C})$. The $\mathrm{p}-\mathrm{I} \kappa \mathrm{B} \alpha / \mathrm{I} \kappa \mathrm{B} \alpha$ ratio was also significantly increased over time ( $0 \mathrm{~min}, 0.082 \pm 0.014 ; 30 \mathrm{~min}, 0.12 \pm 0.01$; $120 \mathrm{~min}, 0.245 \pm 0.026$; Fig. 6D). Thus, the results indicated that $\mathrm{NF}-\kappa \mathrm{B}$ signaling was activated in ADSCs when treated with $100 \mathrm{ng} / \mathrm{ml}$ flagellin.

Effects of F-CM on lung exudation and cell infiltration. The lung/body weight, lung wet/dry weight ratios and the protein concentration in the BALF were detected to evaluate the effects of F-CM on pulmonary edema and vascular permeability (Fig. 7). The mice in the LPS group exhibited significantly higher lung/body weight ratio $(6.69 \pm 0.52 \mathrm{mg} / \mathrm{g}$; Fig. 7A), lung wet/dry weight ratio $(6.01 \pm 0.72 \mathrm{~g} / \mathrm{g}$; Fig. $7 \mathrm{~B})$ and protein concentrations $(639.1 \pm 40.23 \mu \mathrm{g} / \mathrm{ml}$; Fig. 7C) compared with the mice in the control group $(5.70 \pm 0.36 \mathrm{mg} / \mathrm{g} ; 4.13 \pm 0.42 \mathrm{~g} / \mathrm{g}$; and $362.1 \pm 32.36 \mu \mathrm{g} / \mathrm{ml}$, respectively). Moreover, both $\mathrm{CM}$ and F-CM significantly decreased the lung/body weight ratio (CM, 6.02 $\pm 0.46 \mathrm{mg} / \mathrm{g}$; F-CM, 5.71 $\pm 0.51 \mathrm{mg} / \mathrm{g}$ ), lung wet/dry weight ratio $(\mathrm{CM}, 5.04 \pm 0.65 \mathrm{~g} / \mathrm{g} ; \mathrm{F}-\mathrm{CM}, 4.47 \pm 0.58 \mathrm{~g} / \mathrm{g})$ and protein concentrations (CM, 463.8 $\pm 36.48 \mu \mathrm{g} / \mathrm{ml}$; F-CM, $388.5 \pm 57.51 \mu \mathrm{g} / \mathrm{ml}$ ) compared with LPS, but the effects of F-CM were more prominent.

The effect of F-CM on inflammatory cell recruitment was investigated by counting the cell numbers in the BALF. LPS significantly increased not only the total cell number (42.67 $\pm 4.3510^{5} / 1$; Fig. 7D), but also the number of inflammatory cells, including macrophages $\left(11.63 \pm 1.7810^{5} / 1\right.$; Fig. $\left.7 \mathrm{~F}\right)$ and neutrophils $\left(22.78 \pm 2.3310^{5} / \mathrm{l}\right.$; Fig. 7E) compared with the control group. However, the increase in the numbers of total cells, macrophages and neutrophils was significantly inhibited by CM $\left(24.92 \pm 3.7510^{5} / 1 ; 8.04 \pm 1.4310^{5} / 1\right.$; and $11.77 \pm 1.4310^{5} / 1$, respectively) and F-CM (19.56 $\pm 2.3810^{5} / 1 ; 5.99 \pm 1.1610^{5} / 1$; and $8.39 \pm 1.6210^{5} / 1$, respectively). In addition, the BALF of mice 
A

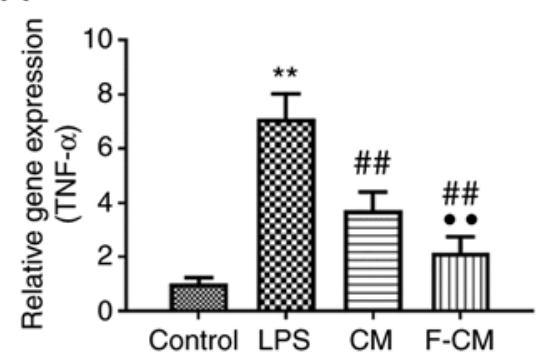

D

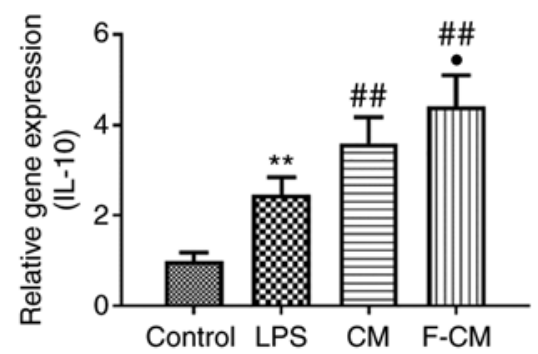

B

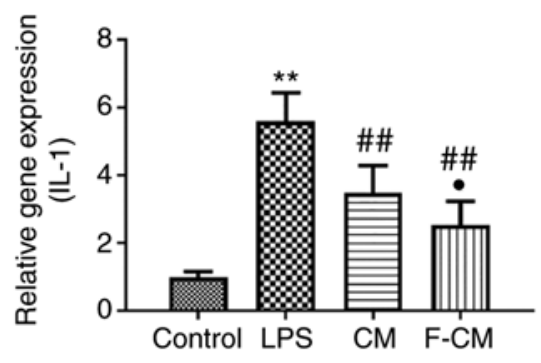

E

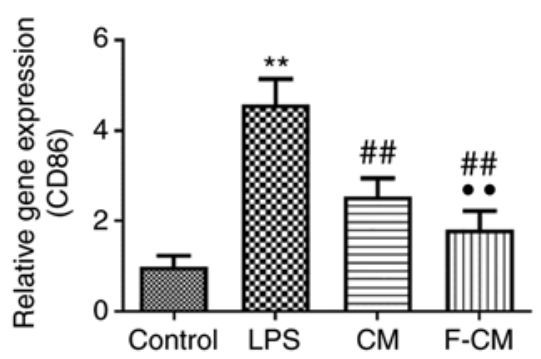

C

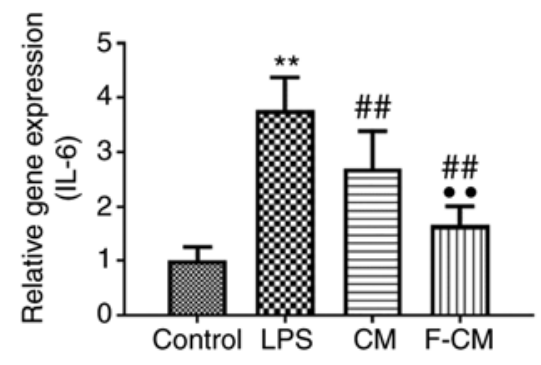

F

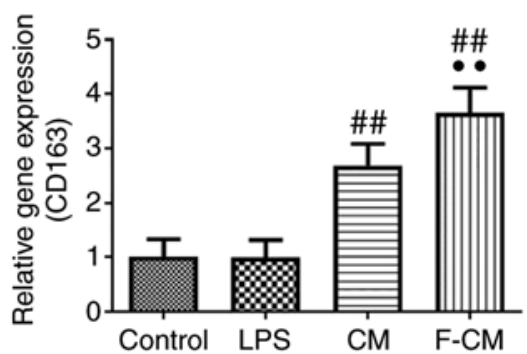

Figure 3. Effects of F-CM on expressions of inflammatory-related genes of murine macrophages. F-CM significantly suppressed the expression levels of (A) TNF- $\alpha$, (B) IL-1, (C) IL-6 and (E) CD86, but enhanced the expression levels of (D) IL-10 and (F) CD163 in flagellin-activated RAW264.7 macrophages. Differences among groups were examined for statistical significance using ANOVA. The results are represented as a relative ratio to the control group. ${ }^{* *} \mathrm{P}<0.01$ vs. control group; ${ }^{\# \#} \mathrm{P}<0.01$ vs. LPS group; ${ }^{\bullet} \mathrm{P}<0.05$ and ${ }^{\bullet \bullet} \mathrm{P}<0.01$ vs. CM group. CM, conditioned medium; F-CM, flagellin-conditioned medium; LPS, lipopolysaccharide; IL, interleukin; TNF, tumor necrosis factor.
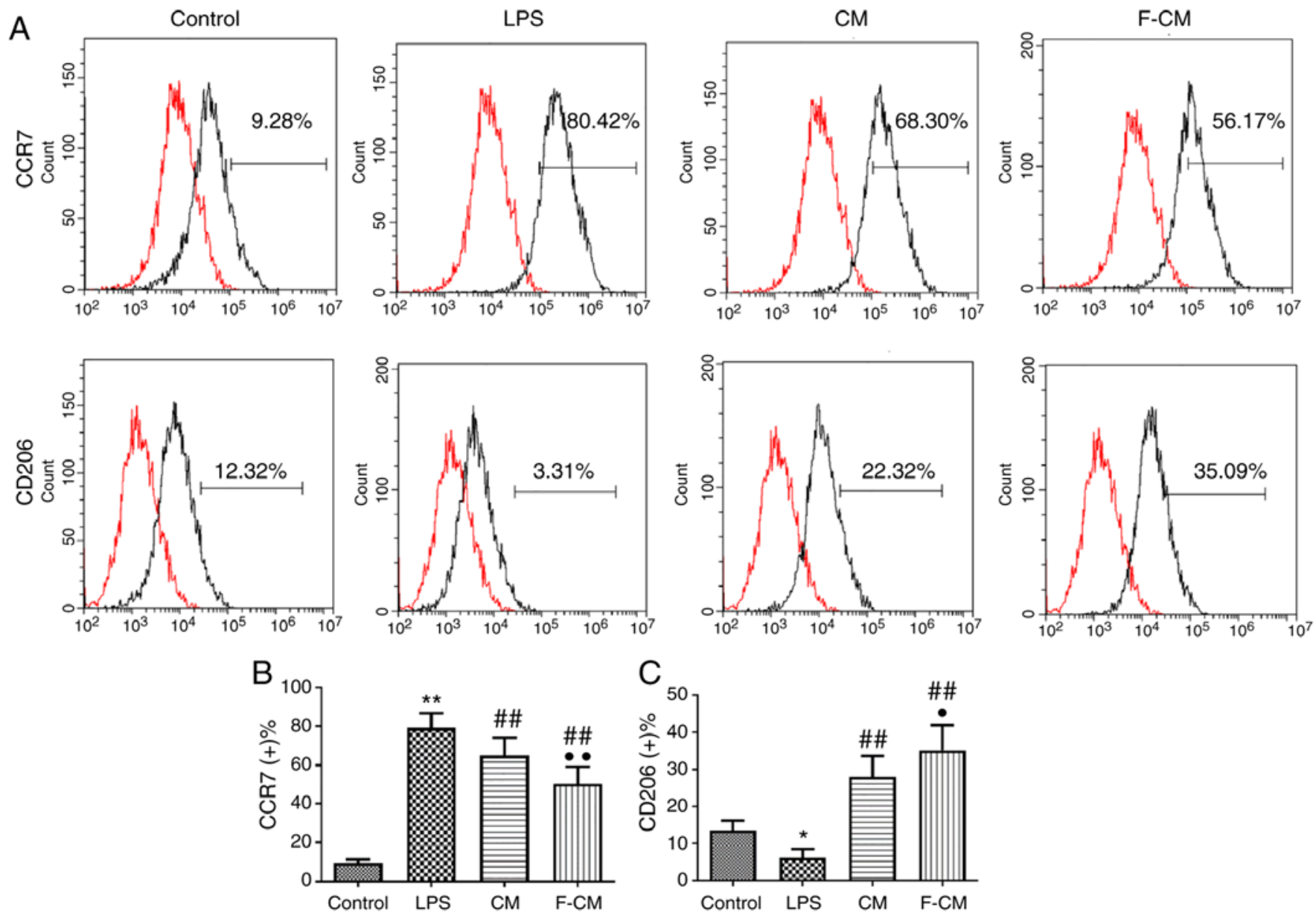

Figure 4. Effects of F-CM on surface markers of human macrophages. (A) Flow cytometric analysis of (B) CCR7 positive cells represent M1 macrophages and (C) CD206 positive cells represent M2 macrophages. Differences among groups were examined for statistical significance using ANOVA. ${ }^{*} \mathrm{P}<0.05$ and ${ }^{* *} \mathrm{P}<0.01$ vs. control group; ${ }^{\# \#} \mathrm{P}<0.01$ vs. LPS group; ${ }^{\bullet} \mathrm{P}<0.05$ and ${ }^{\bullet \bullet} \mathrm{P}<0.01$ vs. CM group. CM, conditioned medium; F-CM, flagellin-conditioned medium; LPS, lipopolysaccharide; CCR, C-C chemokine receptor. 
A
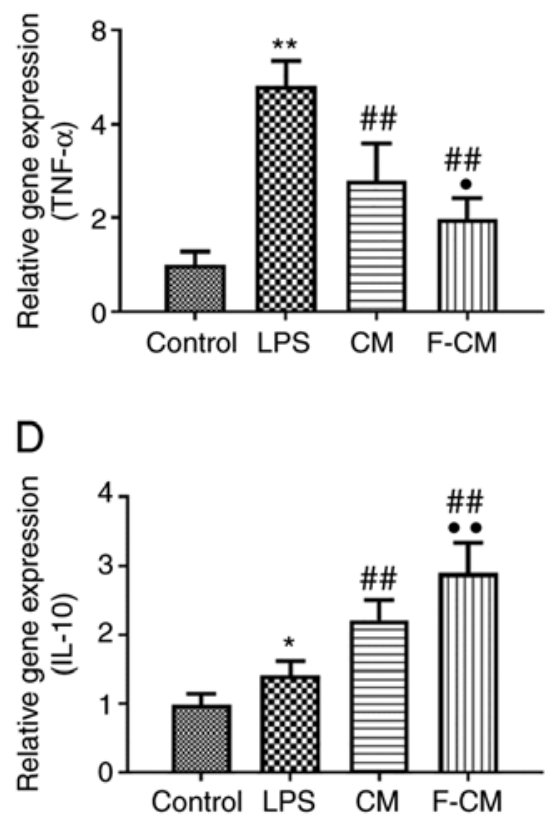

B
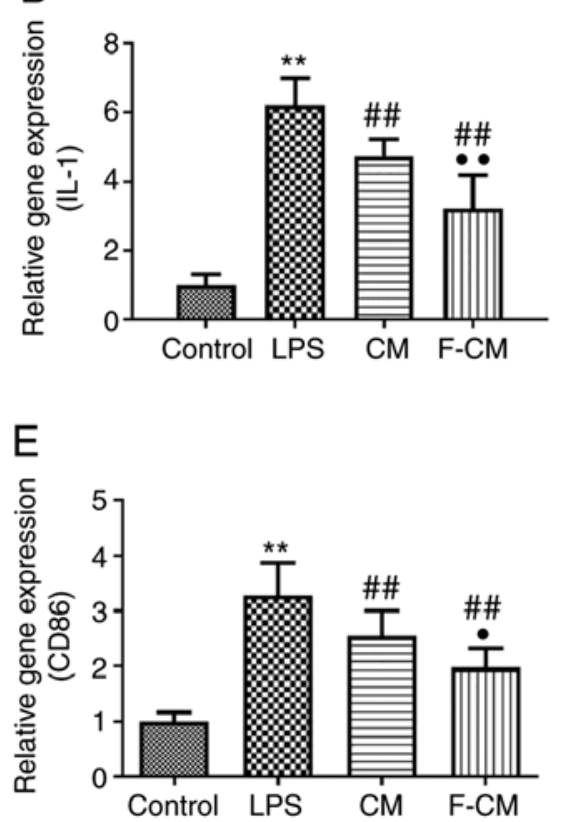
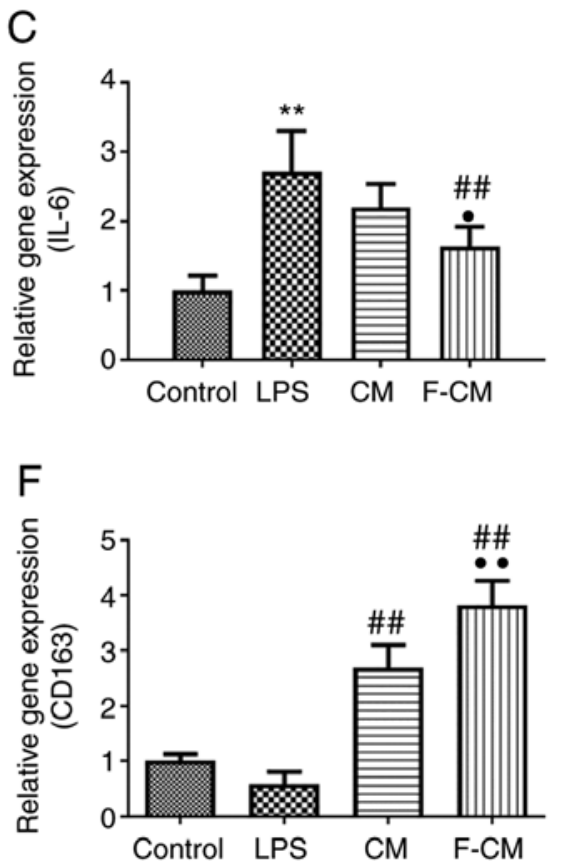

Figure 5. Effects of F-CM on expression levels of inflammatory-related genes of human macrophages. F-CM significantly suppressed the expression of (A) TNF- $\alpha$, (B) IL-1, (C) IL-6 and (F) CD86, but enhanced the expression levels of (D) IL-10 and (E) CD163 in flagellin-activated THP-1 macrophages. Differences among groups were examined for statistical significance using ANOVA. The results are represented as a relative ratio to the control group. ${ }^{*} \mathrm{P}<0.05$ and ${ }^{* *} \mathrm{P}<0.01$ vs. control group; ${ }^{\# \#} \mathrm{P}<0.01$ vs. LPS group; ${ }^{\bullet} \mathrm{P}<0.05$ and ${ }^{\bullet} \mathrm{P}<0.01$ vs. CM group. CM, conditioned medium; F-CM, flagellin-conditioned medium; LPS, lipopolysaccharide; IL, interleukin; TNF, tumor necrosis factor.

treated with F-CM contained the fewest macrophages and neutrophils among mice undergoing a LPS challenge.

Effects of F-CM on reducing inflammation caused by LPS in an animal model. H\&E staining was performed to determine the histological changes in the lung. In the control group, the pulmonary architecture was intact and the alveoli were uniform in size (Fig. 8A). Compared with the control group, the LPS group exhibited marked inflammatory changes, characterized by large areas of red serum, swelling of the alveolar walls and numerous infiltrating inflammatory cells (Fig. 8B). However, the histological changes caused by LPS administration were reversed by CM and F-CM (Fig. 8C and D). Moreover, lung injury score evaluation also identified the treatment effects of CM and F-CM (Fig. 8E). The LPS group (mean, 12.5) had significantly higher lung score compared with the control group (mean, 1.38), but the lung injury score in F-CM group (mean, 5.13) was significantly lower compared with the LPS group. However, no significant differences were found between the CM (mean, 7.75) and LPS groups.

ELISA was performed to investigate the levels of inflammatory mediators involved in ALI. The mice in the LPS group had significantly higher levels of TNF- $\alpha(704.6 \pm 87.1 \mathrm{pg} / \mathrm{ml})$, IL-1 (399.8 \pm 61.90 pg/ml), IL-6 (249.4 \pm 54.71 pg/ml), MCP-1 $(370.8 \pm 67.46 \mathrm{pg} / \mathrm{ml})$ and IL-10 $(82.50 \pm 15.32 \mathrm{pg} / \mathrm{ml})$ compared with the mice in the control group $(117.5 \pm 52.7 ; 42.75 \pm 26.68$; $61.25 \pm 24.06 ; 44.25 \pm 21.02 \mathrm{pg} / \mathrm{ml}$; and $15.75 \pm 10.18$, respectively; Fig. 9A-E). Consistent with the results from the in vitro study, CM and F-CM significantly reduced the production of TNF- $\alpha$ (CM, 413.3 \pm 96.05 pg/ml; F-CM, 263.4 $\pm 0.58 \mathrm{pg} / \mathrm{ml})$,

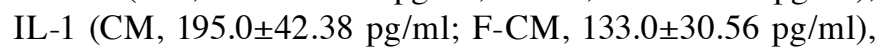
IL-6 (CM, $187.4 \pm 44.4$ pg/ml; F-CM, 138.0 \pm 33.79 pg/ml) and

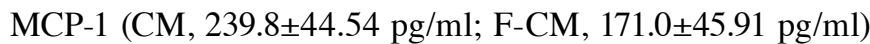
compared with PBS. However, no differences in IL-10 (CM, $74.13 \pm 13.20 \mathrm{pg} / \mathrm{ml}$; F-CM, 73.88 $\pm 15.49 \mathrm{pg} / \mathrm{ml}$ ) levels were observed among the LPS, CM and F-CM groups. It was also demonstrated that the F-CM group had significantly lower TNF- $\alpha$, IL-1 and MCP-1 levels compared with the CM group. In addition, the F-CM group (3.57 \pm 0.93$)$ had a significantly lower TNF- $\alpha /$ IL-10 ratio compared with the LPS group $(8.54 \pm 1.06)$ and the CM group (5.58 \pm 1.30 ; Fig. 9F). However, no significant difference in TNF- $\alpha /$ IL-10 ratio was found between the Control (7.21 \pm 2.14$)$ and LPS group.

\section{Discussion}

The causes of ALI include a disruption in the balance of proand anti-inflammatory factors, an imbalance between oxidation and anti-oxidation, disorders of the coagulation system and abnormal apoptosis (31). In particular, LPS, which comprises part of the wall of Gram-negative bacteria, can increase the expression of inflammatory factors, promote inflammatory cells to enter lung tissue and increase alveolar-capillary barrier permeability $(28,32)$. Thus, the focus of treating ALI is to inhibit the LPS-induced inflammatory reaction (29). Despite their effectiveness in regulating inflammation, the heavy use of steroids is associated with severe adverse effects and may increase the risk of infection (32). Moreover, other therapeutic methods, such as mechanical ventilation, neuromuscular blocking agents and antimicrobial therapy, are only moderately effective (7).

Previous clinical studies reported that the use of MSCs is safe for patients with ARDS, with a superior anti-inflammatory effect $(7,33)$. In addition, as the principal beneficial 

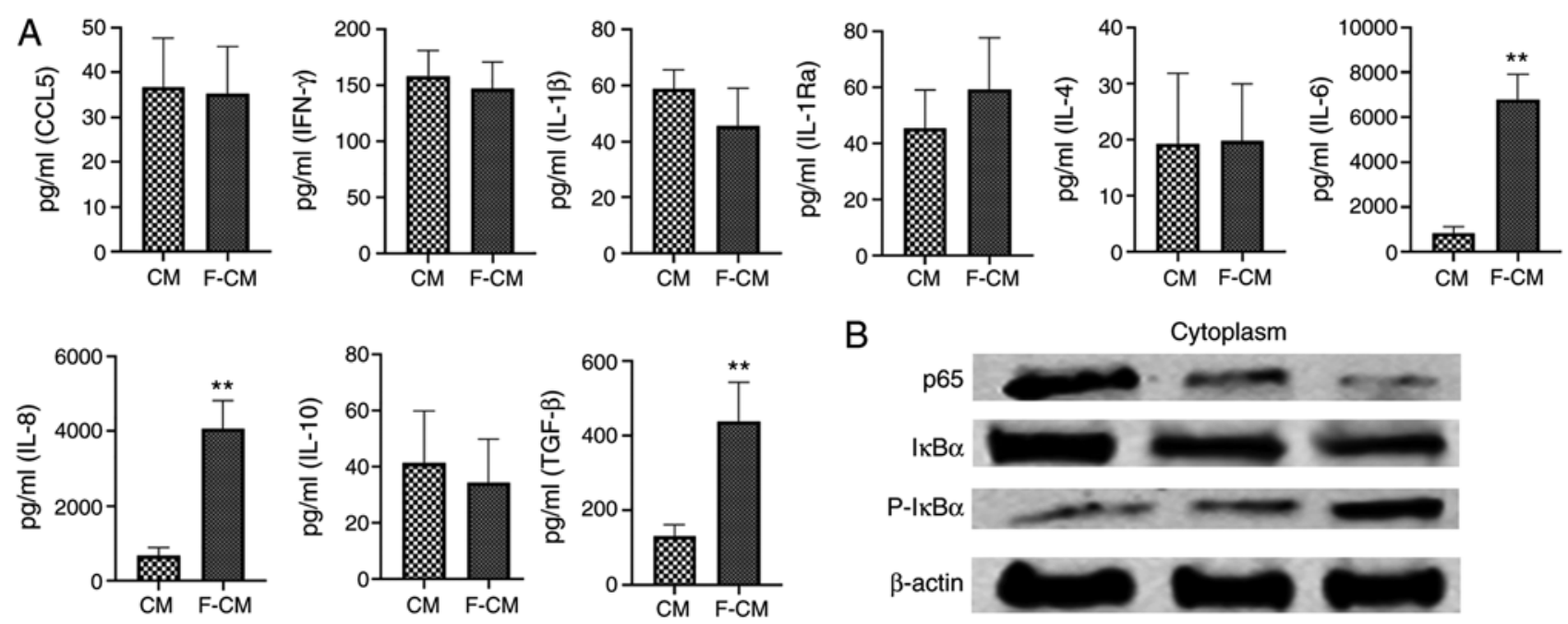

B
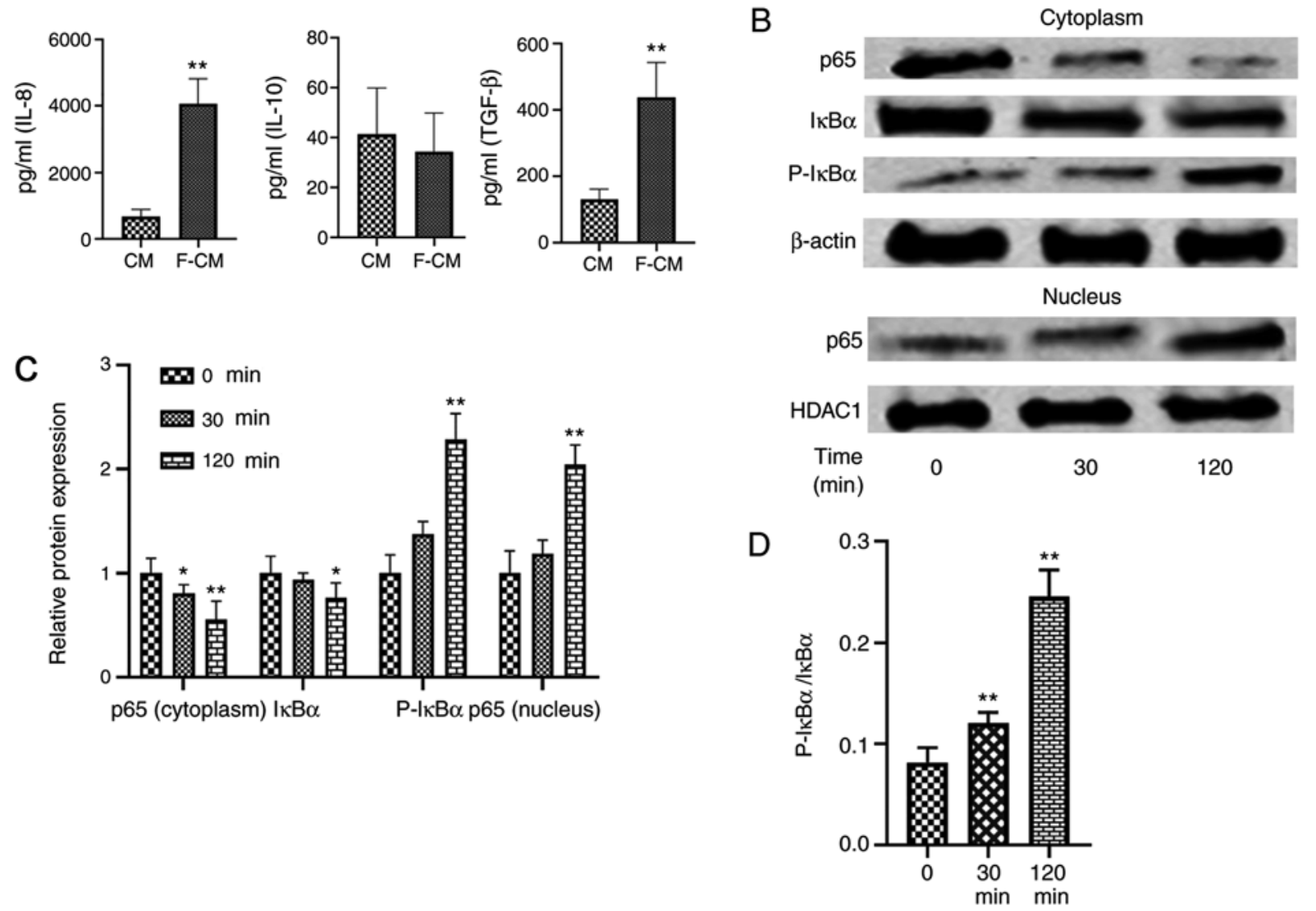

Figure 6. Effects of flagellin preconditioning on the production of inflammatory-related cytokines and NF-kB signaling pathway in ADSCs. (A) Levels of inflammation-related cytokines of MSCs and flagellin-activated MSCs. Differences between groups were examined for statistical significance using Student's t-test. ${ }^{* *} \mathrm{P}<0.01$ vs. CM group. (B) p65, IкB $\alpha$ and $\mathrm{p}$-IкB $\alpha$ protein expression levels in the cytoplasm and p65 protein expression in nucleus were examined using western blotting. (C) Changes of protein expressions (cytoplasm p65, cytoplasm $1 \kappa B \alpha$, cytoplasm $p$ - $1 \kappa B \alpha$ and nucleus $p 65$ ) and (D) $p$-IкB $\alpha / 1 \kappa B \alpha$ ratio during incubation. Differences among groups were examined for statistical significance using ANOVA. The results are represented as a relative ratio to the 0 min groups. ${ }^{*} \mathrm{P}<0.05$ and ${ }^{* *} \mathrm{P}<0.01$ vs. 0 min group. $\mathrm{CM}$, conditioned medium; F-CM, flagellin-conditioned medium; p-, phosphorylated; IкB, inhibitor of NF-kB; IL, interleukin; CCL, C-C chemokine ligand; IFN, interferon; TGF, transforming growth factor; HDAC1, histone deacetylase 1; IL-1Ra, IL-1 receptor antagonist.

effects of MSCs are mediated via paracrine mechanisms, CM from MSCs may be a promising therapeutic approach to ALI (26). However, the concentration of biofactors in CM is considered insufficient for therapy; thus, CM must be concentrated for treatment. Furthermore, external stimuli can alter the composition of paracrine factors from MSCs, making them more useful in the treatment of particular diseases. For instance, exposing MSCs to pro-inflammatory cytokines for a short time, which mimics the acute inflammatory microenvironment, significantly enhances their anti-inflammatory effects $(13,19)$. Flagellin is a potent activator of a broad range of cell types involved in innate and adaptive immunity. Following stimulation of TLR5-expressing cells with flagellin, a signaling cascade is triggered, which involves phosphorylation of IL-1 receptor-associated kinase 1, leading to activation of mitogen-activated protein kinase kinases and inhibitor of
NF- $\kappa \mathrm{B}$ kinases, ultimately activating inflammatory protein production via NF- $\kappa \mathrm{B}$ and $\mathrm{p} 38$ mitogen-activated protein kinase (24). However, most previous studies have focused on the beneficial effects of ADSCs activated by cytokines such as TNF- $\alpha$, IL-1 $\beta$ and IFN- $\gamma(17,19,34)$. Thus, limited information is available regarding the immunomodulatory properties of flagellin-exposed ADSCs.

In the present study, the MSC markers CD73, CD90 and CD105 were highly expressed in flagellin-activated ADSCs, while the expression levels of the endothelial cell marker CD31 and the hematopoietic cell marker CD45 were low, suggesting that flagellin preconditioning at $100 \mathrm{ng} / \mathrm{ml}$ for 2 days did not affect the characteristics of ADSCs. Since FBS may induce severe immune rejection, serum-free DMEM was used to collect paracrine factors from MSCs. Although serum-free incubation decreased the viability of 
A
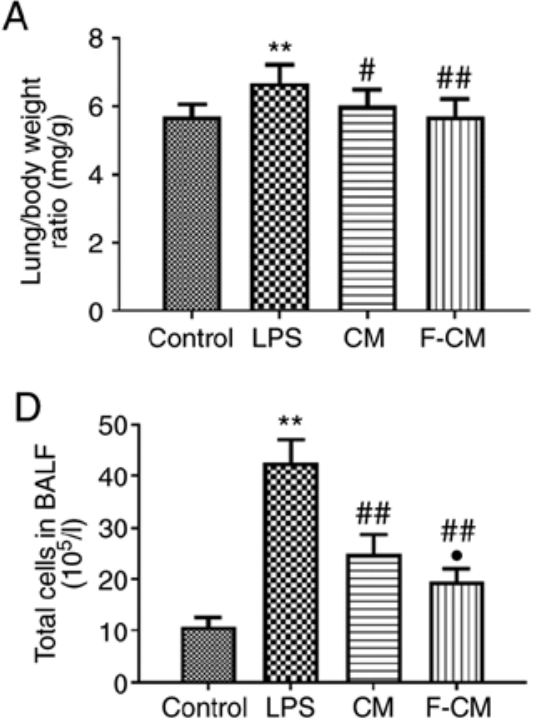

B

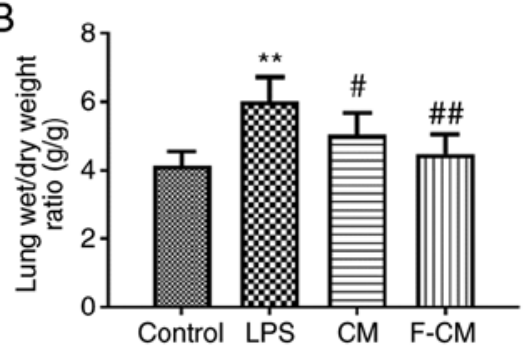

E

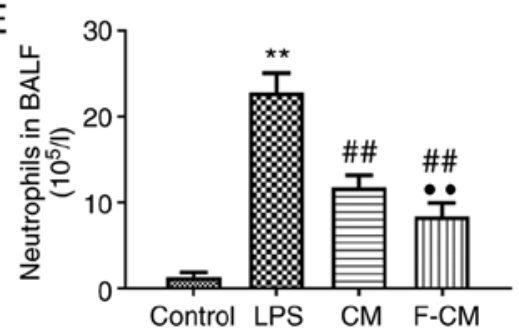

C

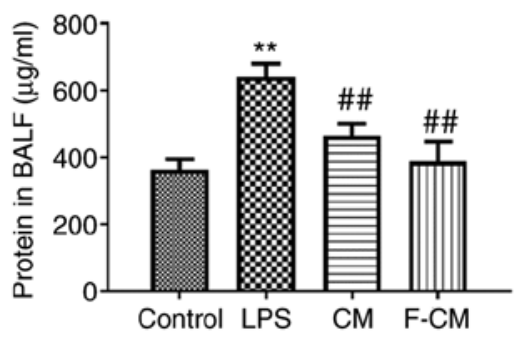

$\mathrm{F}$

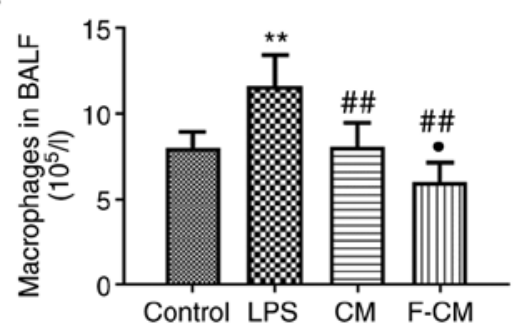

Figure 7. Effects of F-CM on lung exudation and cell infiltration. A total of $24 \mathrm{~h}$ after the intratracheal instillation of LPS, (A) lung/body weight ratio and (B) lung wet/dry weight ratio were calculated. (C) Total protein concentration, (D) total cells, (E) neutrophils and (F) macrophages in the BALF were measured. Differences among groups were examined for statistical significance using ANOVA. ${ }^{* *} \mathrm{P}<0.01$ vs. control group; ${ }^{\#} \mathrm{P}<0.05$ and ${ }^{\# \#} \mathrm{P}<0.01$ vs. LPS group; ${ }^{\bullet} \mathrm{P}<0.05$ and ${ }^{\bullet} \mathrm{P}<0.01$ vs. CM group. CM, conditioned medium; F-CM, flagellin-conditioned medium; BALF, bronchoalveolar lavage fluid; LPS, lipopolysaccharide.
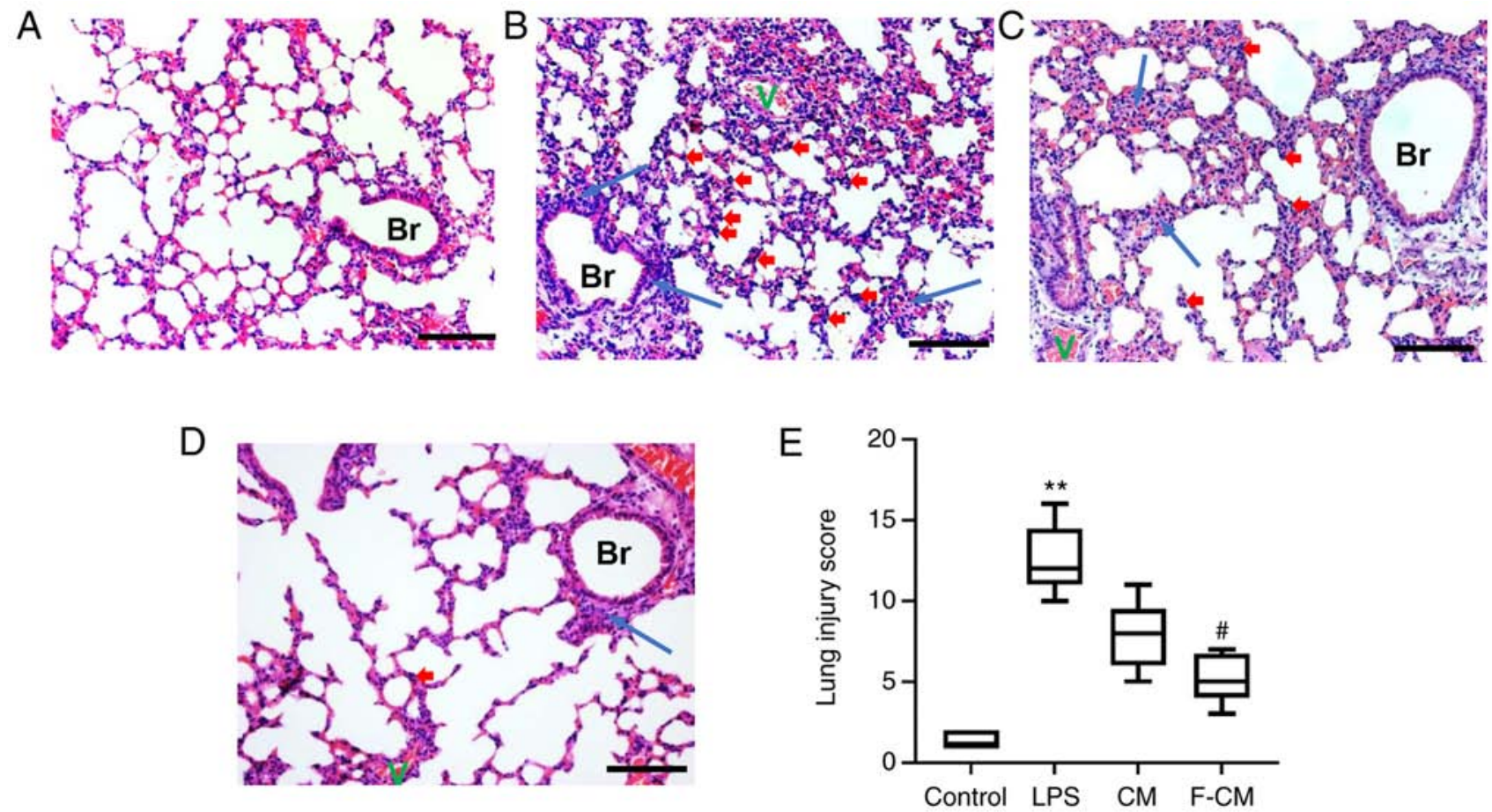

Figure 8. Effects of F-CM on reducing pathological damages caused by LPS. Pathological examination of the lung tissues of the (A) control, (B) LPS, (C) CM and (D) F-CM groups $24 \mathrm{~h}$ after LPS challenge. (E) Lung injury score was analyzed using the Kruskal-Wallis test. Differences among groups were examined for statistical significance by Kruskal-Wallis with Dunn's post hoc test. Red arrows indicate infiltrated immune cells, and blue arrows indicate edema. Br indicates bronchia, and $\mathrm{V}$ indicates vessels. Scale bar, $100 \mu \mathrm{m}$. ${ }^{* *} \mathrm{P}<0.01$ vs. control group; ${ }^{*} \mathrm{P}<0.05$ vs. LPS group. CM, conditioned medium; F-CM, flagellin-conditioned medium; LPS, lipopolysaccharide.

ADSCs, flagellin-activated ADSCs retained $73 \%$ viability after $48 \mathrm{~h}$. Previous studies have reported that LPS, a TLR5 ligand, could protect MSCs from serum deprivation by stabilizing cell membrane and activating ERK and PI3K/Akt signaling pathways $(35,36)$. Given the similarities between TLR4 and TLR5, flagellin may exert its beneficial effects in similar ways (23). Therefore, ultrafiltration units with a
3-kDa molecular weight cutoff were used to concentrate CM, to retain the highest number of inflammatory regulators as possible.

Alveolar macrophages include tissue-resident and recruited macrophages, and account for $80 \%$ of permanent alveolar cells (6). Alveolar macrophages phagocytize foreign bodies, recognize antigens and secrete a variety of inflammatory 
A
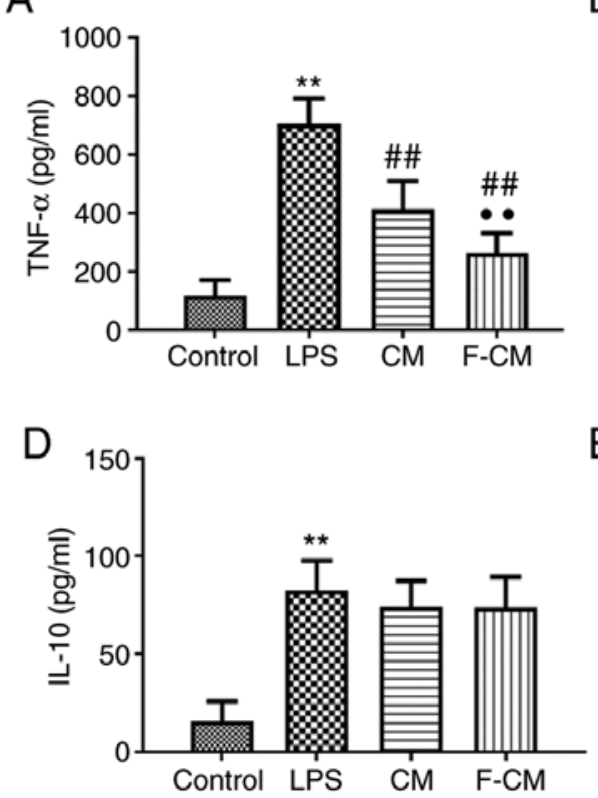

B

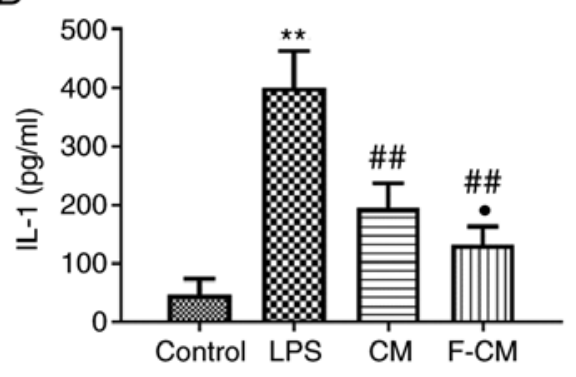

E

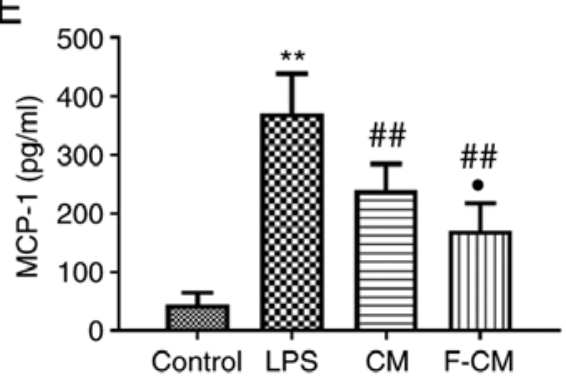

C

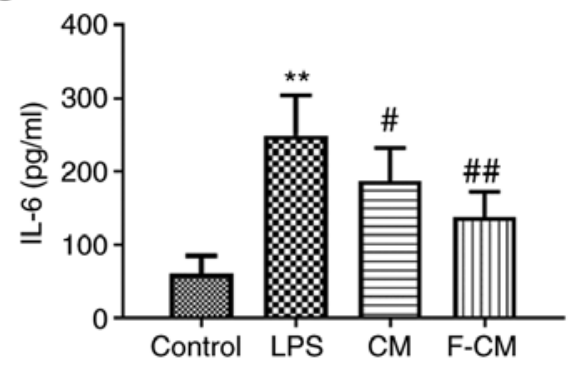

F

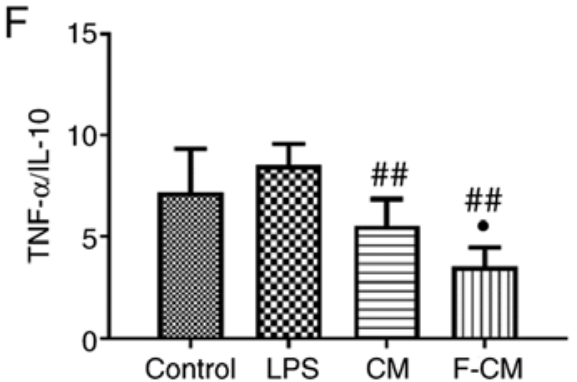

Figure 9. Effects of F-CM on inflammation-related factors. Expression levels of (A) TNF- $\alpha$, (B) IL-1, (C) IL-6, (D) IL-10 and (E) MCP-1 in the lung were determined using ELISA $24 \mathrm{~h}$ after LPS administration. (F) TNF- $\alpha / \mathrm{IL}-10$ ratio was also calculated. Differences among groups were examined for statistical significance using ANOVA. ${ }^{* *} \mathrm{P}<0.01$ vs. control group; ${ }^{\#} \mathrm{P}<0.05$ and ${ }^{\# \#} \mathrm{P}<0.01$ vs. LPS group; ${ }^{\bullet} \mathrm{P}<0.05$ and ${ }^{\bullet \bullet} \mathrm{P}<0.01$ vs. CM group. CM, conditioned medium; F-CM, flagellin-conditioned medium; LPS, lipopolysaccharide; TNF, tumor necrosis factor; IL, interleukin; MCP, monocyte chemoattractant protein.

factors, forming the first line of the host immune defense (6). Macrophages exhibit high functional plasticity and may be induced into different phenotypes when subjected to different biosignals (37). In general, macrophages may be divided into classically activated (M1) and alternatively activated (M2) macrophages. M1 macrophages usually serve a pro-inflammatory role and can secrete several pro-inflammatory factors, such as TNF- $\alpha$, IL-1, and IL-6, which contribute to the clearance of pathogens (38). In contrast, M2 macrophages secrete anti-inflammatory factors, such as IL-10, and promote angiogenesis, wound healing and tissue remodeling (39). The present in vitro study demonstrated that CM from flagellin-activated ADSCs significantly enhanced the expression of the anti-inflammatory M2 macrophage marker CD163 and decreased the expression of the inflammatory M1 macrophage marker CD86 compared with CM from the regular ADSC model. These results indicated the superior ability of F-CM to regulate macrophage characteristics and immunosuppression.

To investigate the mechanism underlying the superior anti-inflammatory effects of F-CM, the cytokines responsible for the immunomodulatory properties of the $\mathrm{CM}$ were investigated. Since the composition of $\mathrm{CM}$ is complex, flagellin preconditioning significantly increased the levels of both pro-inflammatory (IL-6 and IL-8) and anti-inflammatory cytokines (TGF- $\beta$ ). Although IL-6 is considered as a pro-inflammatory cytokine, it may exert both pro-inflammatory and anti-inflammatory roles (37). Previous studies revealed that IL- 6 can induce macrophages into the M2 phenotype in an animal model $(37,40)$. Furthermore, Liu et al (15) and Chen et al (41) reported that MSCs reprogramed macrophages into the M2 phenotype mainly by secreting TGF- $\beta$. Therefore, the increased IL-6 and TGF- $\beta$ levels may partly explain the beneficial effects of flagellin preconditioning. In the current study, western blotting results indicated that $\mathrm{NF}-\kappa \mathrm{B}$ signaling was activated in ADSCs after treatment with $100 \mathrm{ng} / \mathrm{ml}$ flagellin for $30 \mathrm{~min}$, which may partly explain the reason for the altered cytokines levels.

An LPS-induced ALI mouse model was used in the present study, as its reliability and reproducibility have been previously confirmed (42). The results of the examination of the lung exudate, H\&E staining and cell counting in the BALF identified that both CM and F-CM significantly prevented LPS-induced lung injury in mice, and the effects of F-CM treatment were superior. Furthermore, the levels of inflammation-related factors in the BALF were detected using ELISA. TNF- $\alpha$ is an inflammatory factor that increases rapidly in the early stages of inflammation (43). TNF- $\alpha$ can mobilize bone marrow leukocytes into the blood circulation, aggregate monocytes in the lung tissue and promote the release of inflammatory factors, such as IL-1, IL-6 and colony-stimulating factor (44). The role of IL-1 has numerous similarities with that of TNF- $\alpha$ in ALI caused by inflammation (45). For example, IL-1 can initiate inflammatory reactions together with $\mathrm{TNF}-\alpha$, and enhance lung injury induced by TNF- $\alpha$, but it does not itself cause lung injury (46). IL-6 can further promote macrophage aggregation, enhance phagocytosis by macrophages and promote the expression of various inflammatory factors (47). MCP-1 is another inflammatory chemokine that regulates the chemotactic response of leukocytes to inflammatory stimuli (48). Moreover, IL-10 is a general immunosuppressive cytokine, which has been shown to promote the conversion of M1 macrophages into M2 macrophages, as well as counteract the pro-inflammatory effects of TNF- $\alpha$ (47). 
In the present study, LPS challenge not only increased the levels of pro-inflammatory cytokines, but also those of the anti-inflammatory cytokine IL-10 in mice, suggesting that the anti-inflammation process was activated. F-CM significantly decreased the production of TNF- $\alpha$, IL-1, IL-6 and MCP-1; however, there were no significant differences in IL-10 among the LPS, CM and F-CM groups, possibly because the alleviated inflammation reaction was associated with lowered production of anti-inflammatory factors. Previous studies have reported that drug interventions, such as Jaceosidin and Ginsenoside $\mathrm{Rh} 2$, greatly decreased the levels of pro-inflammatory cytokines, but do not alter the level of IL-10 $(28,49,50)$. Thus, the TNF- $\alpha /$ IL-10 ratio may be a more suitable indicator of the anti-inflammatory effect. However, IL-10 can be produced by almost all leukocytes, including macrophages, dendritic cells, neutrophils, natural killer cells, B cells and T cells (43). Currently, the effects of CM on cells other than macrophages remain unknown. In addition, the reasons for the absence of an increase in IL-10 require further investigation.

Despite the promising results, there were several limitations to the present study. Due to the limited time and the complexity of CM (including exosomes, cytokines and microRNAs), only the changes in nine important cytokines in the CM following flagellin preconditioning were examined. Although it was found that three cytokines changed significantly after ADCSs were preconditioned with flagellin, which one serves the key role in regulating the polarization of macrophages and inhibiting inflammation is yet to be elucidated. Furthermore, only one F-CM administration mode was evaluated in the present study, and additional experiments are required to determine the optimal dosage and timing of administration.

In conclusion, the results of the present study suggested that flagellin preconditioning significantly enhanced the beneficial effects of CM from ADSCs against LPS-induced lung injury in mice. These findings may indicate a promising novel approach to the treatment of inflammation-induced ALI.

\section{Acknowledgements}

Not applicable.

\section{Funding}

This study was supported by the Shanghai International Science and Technology Cooperation Fund (grant no. 18410721300).

\section{Availability of data and materials}

The datasets used and/or analyzed during the current study are available from the corresponding author on reasonable request.

\section{Authors' contributions}

$\mathrm{XD}$ and RL collaborated to design the study. RL was responsible for experiments. YL analyzed the data and prepared the manuscript. All authors read and approved the final manuscript.

\section{Ethics approval and consent to participate}

Not applicable (MSCs were purchased from the Type Culture Collection of the Chinese Academy of Sciences).

\section{Patient consent for publication}

Not applicable.

\section{Competing interests}

The authors declare that they have no competing interests.

\section{References}

1. Villar J, Blanco J and Kacmarek RM: Current incidence and outcome of the acute respiratory distress syndrome. Curr Opin Crit Care 22: 1-6, 2016.

2. Patel VJ, Biswas Roy S, Mehta HJ, Joo M and Sadikot RT: Alternative and natural therapies for acute lung injury and acute respiratory distress syndrome. Biomed Res Int 2018: 2476824, 2018.

3. Herrero R, Sanchez G and Lorente JA: New insights into the mechanisms of pulmonary edema in acute lung injury. Ann Transl Med 6: 32, 2018.

4. Laskin DL, Malaviya R and Laskin JD: Role of macrophages in acute lung injury and chronic fibrosis induced by pulmonary toxicants. Toxicol Sci 168: 287-301, 2019.

5. Chazaud B: Inflammation and skeletal muscle regeneration: Leave it to the macrophages! Trends Immunol 41: 481-492, 2020.

6. Huang X, Xiu H, Zhang S and Zhang G: The role of macrophages in the pathogenesis of ALI/ARDS. Mediators Inflamm 2018: 1264913, 2018.

7. Wilson JG, Liu KD, Zhuo H, Caballero L, McMillan M, Fang X, Cosgrove K, Vojnik R, Calfee CS, Lee JW, et al: Mesenchymal stem (stromal) cells for treatment of ARDS: A phase 1 clinical trial. Lancet Respir Med 3: 24-32, 2015.

8. Li Y,Zhang Z and Zhang Z: Porous chitosan/nano-hydroxyapatite composite scaffolds incorporating simvastatin-loaded PLGA microspheres for bone repair. Cells Tissues Organs 205: 20-31, 2018.

9. Radwan SM, Ghoneim D, Salem M, Saeed M, Saleh Y, Elhamy M, Wael K, Shokair O and Wahdan SA: Adipose tissue-derived mesenchymal stem cells protect against amiodarone-induced lung injury in rats. Appl Biochem Biotechnol 191: 1027-1041, 2020.

10. Hamilton AM, Cheung WY, Gómez-Aristizábal A, Sharma A, Nakamura S, Chaboureau A, Bhatt S, Rabani R, Kapoor M, Foster PJ and Viswanathan S: Iron nanoparticle-labeled murine mesenchymal stromal cells in an osteoarthritic model persists and suggests anti-inflammatory mechanism of action. PLoS One 14: e0214107, 2019.

11. Timmers L, Lim SK, Hoefer IE, Arslan F, Lai RC, van Oorschot AA, Goumans MJ, Strijder C, Sze SK, Choo A, et al: Human mesenchymal stem cell-conditioned medium improves cardiac function following myocardial infarction. Stem Cell Res 6: 206-214, 2011.

12. Zomer HD, Varela GKDS, Delben PB, Heck D, Jeremias TDS and Trentin AG: In vitro comparative study of human mesenchymal stromal cells from dermis and adipose tissue for application in skin wound healing. J Tissue Eng Regen Med 13: 729-741, 2019.

13. Lu Z, Chen Y, Dunstan C, Roohani-Esfahani S and Zreiqat H: Priming adipose stem cells with tumor necrosis factor-alpha preconditioning potentiates their exosome efficacy for bone regeneration. Tissue engineering Part A 23: 1212-1220, 2017.

14. Park HH, Lee S, Yu Y, Yoo SM, Baek SY, Jung N, Seo KW and Kang KS: TGF- $\beta$ secreted by human umbilical cord blood-derived mesenchymal stem cells ameliorates atopic dermatitis by inhibiting secretion of TNF- $\alpha$ and IgE. Stem Cells: Apr 11, 2020 doi: 10.1002/stem.3183. Online ahead of print.

15. Liu F, Qiu H, Xue M, Zhang S, Zhang X, Xu J, Chen J, Yang Y and Xie J: MSC-secreted TGF- $\beta$ regulates lipopolysaccharide-stimulated macrophage M2-like polarization via the Akt/FoxO1 pathway. Stem Cell Res Ther 10: 345, 2019. 
16. Harrell CR, Markovic BS, Fellabaum C, Arsenijevic N, Djonov V and Volarevic V: The role of interleukin 1 receptor antagonist in mesenchymal stem cell-based tissue repair and regeneration. Biofactors 46: 263-275, 2020.

17. Putra A, Ridwan FB, Putridewi AI, Kustiyah AR, Wirastuti K, Sadyah NAC, Rosdiana I and Munir D: The role of TNF- $\alpha$ induced MSCs on suppressive inflammation by increasing TGF- $\beta$ and IL-10. Open Access Maced J Med Sci 6: 1779-1783, 2018.

18. Saparov A, Ogay V, Nurgozhin T, Jumabay M and Chen WC: Preconditioning of human mesenchymal stem cells to enhance their regulation of the immune response. Stem Cells Int 2016: 3924858, 2016.

19. Redondo-Castro E, Cunningham C, Miller J, Martuscelli L, Aoulad-Ali S, Rothwell NJ, Kielty CM, Allan SM and Pinteaux E: Interleukin-1 primes human mesenchymal stem cells towards an anti-inflammatory and pro-trophic phenotype in vitro. Stem Cell Res Ther 8: 79, 2017.

20. Ocansey DKW, Pei B, Yan Y, Qian H, Zhang X, Xu W and Mao F: Improved therapeutics of modified mesenchymal stem cells: An update. J Transl Med 18: 42, 2020.

21. Linard C, Strup-Perrot C, Lacave-Lapalun JV and Benderitter M Flagellin preconditioning enhances the efficacy of mesenchymal stem cells in an irradiation-induced proctitis model. J Leukoc Biol 100: 569-580, 2016.

22. Jafari M, Asghari A, Delbandi AA, Jalessi M, Jazayeri MH, Samarei R and Tajik N: Priming TLR3 and TLR4 in human adipose- and olfactory mucosa-derived mesenchymal stromal cells and comparison of their cytokine secretions. Cytotechnology 72: 57-68, 2020.

23. Evaristo-Mendonça F, Sardella-Silva G, Kasai-Brunswick TH, Campos RMP, Domizi P, Santiago MF, de Melo Reis RA, Mendez-Otero R, Ribeiro-Resende VT and Pimentel-Coelho PM: Preconditioning of rat bone marrow-derived Mesenchymal stromal cells with toll-like receptor agonists. Stem Cells Int 2019: 7692973, 2019

24. He L, Liang Y, Yu X, Peng W, He J, Fu L, Lin H, Zhang Y and Lu D: Vibrio parahaemolyticus flagellin induces cytokines expression via toll-like receptor 5 pathway in orange-spotted grouper, Epinephelus coioides. Fish Shellfish Immunol 87: 573-581, 2019

25. Li Y, Huang L, Cai Z, Deng W, Wang P, Su H, Wu Y and Shen $\mathrm{H}$ : A study of the immunoregulatory function of TLR3 and TLR4 on mesenchymal stem cells in ankylosing spondylitis. Stem Cells Dev 28: 1398-1412, 2019

26. Su VY, Lin CS, Hung SC and Yang KY: Mesenchymal stem cell-conditioned medium induces neutrophil apoptosis associated with inhibition of the NF- $\kappa \mathrm{B}$ pathway in endotoxin-induced acute lung injury. Int J Mol Sci 20: 2208, 2019.

27. Livak KJ and Schmittgen TD: Analysis of relative gene expression data using real-time quantitative PCR and the 2(-Delta Delta C(T)) method. Methods 25: 402-408, 2001.

28. Huang XL, Wei XC, Guo LQ, Zhao L, Chen XH, Cui YD, Yuan J, Chen DF and Zhang J: The therapeutic effects of Jaceosidin on lipopolysaccharide-induced acute lung injury in mice. J Pharmacol Sci 140: 228-235, 2019.

29. Li L, Dong L, Zhang J, Gao F, Hui J and Yan J: Mesenchymal stem cells with downregulated Hippo signaling attenuate lung injury in mice with lipopolysaccharideinduced acute respiratory distress syndrome. Int J Mol Med 43: 1241-1252, 2019.

30. Smith KM, Mrozek JD, Simonton SC, Bing DR, Meyers PA, Connett JE and Mammel MC: Prolonged partial liquid ventilation using conventional and high-frequency ventilatory techniques: Gas exchange and lung pathology in an animal model of respiratory distress syndrome. Crit Care Med 25: 1888-1897, 1997.

31. Teixeira JP, Ambruso S, Griffin BR and Faubel S: Pulmonary consequences of acute kidney injury. Semin Nephrol 39: 3-16, 2019.

32. Pedrazza L, Cunha AA, Luft C, Nunes NK, Schimitz F, Gassen RB, Breda RV, Donadio MV, de Souza Wyse AT, Pitrez PMC, et al: Mesenchymal stem cells improves survival in LPS-induced acute lung injury acting through inhibition of NETs formation. J Cell Physiol 232: 3552-3564, 2017.

33. Matthay MA, Calfee CS, Zhuo H, Thompson BT, Wilson JG, Levitt JE, Rogers AJ, Gotts JE, Wiener-Kronish JP, Bajwa EK, et al: Treatment with allogeneic mesenchymal stromal cells for moderate to severe acute respiratory distress syndrome (START study): A randomised phase 2a safety trial. Lancet Respir Med 7: 154-162, 2019.
34. Zhu M, Chu Y, Shang Q, Zheng Z, Li Y, Cao L, Chen Y, Cao J, Lee OK, Wang Y, et al: Mesenchymal stromal cells pretreated with pro-inflammatory cytokines promote skin wound healing through VEGFC-mediated angiogenesis. Stem Cells Transl Med: Jun 13, 2020 (Epub ahead of print).

35. Wang J, Li Z, Zhang Y, Liu X, Chen L and Chen Y: CX43 change in LPS preconditioning against apoptosis of mesenchymal stem cells induced by hypoxia and serum deprivation is associated with ERK signaling pathway. Mol Cell Biochem 380: 267-275, 2013.

36. Wang ZJ, Zhang FM, Wang LS, Yao YW, Zhao Q and Gao X: Lipopolysaccharides can protect mesenchymal stem cells (MSCs) from oxidative stress-induced apoptosis and enhance proliferation of MSCs via Toll-like receptor(TLR)-4 and PI3K/Akt. Cell Biol Int 33: 665-674, 2009.

37. Chen L, Wang S, Wang Y, Zhang W, Ma K, Hu C, Zhu H, Liang S, Liu M and Xu N: IL-6 influences the polarization of macrophages and the formation and growth of colorectal tumor. Oncotarget 9: 17443-17454, 2018

38. Rana AK, Li Y, Dang Q and Yang F: Monocytes in rheumatoid arthritis: Circulating precursors of macrophages and osteoclasts and, their heterogeneity and plasticity role in RA pathogenesis. Int Immunopharmacol 65: 348-359, 2018

39. Terai S, Ueda-Hayakawa I, Nguyen CTH, Ly NTM, Yamazaki F, Kambe N, Son Y and Okamoto H: Palisaded neutrophilic and granulomatous dermatitis associated with systemic lupus erythematosus: Possible involvement of CD163(+) M2 macrophages in two cases, and a review of published works. Lupus 27: 2220-2227, 2018.

40. Braune J, Weyer U, Hobusch C, Mauer J, Brüning JC, Bechmann I and Gericke M: IL- 6 regulates M2 polarization and local proliferation of adipose tissue macrophages in obesity. J Immunol 198: 2927-2934, 2017.

41. Chen X, Yang B, Tian J, Hong H, Du Y, Li K, Li X, Wang N, Yu X and Wei X: Dental follicle stem cells ameliorate lipopolysaccharide-induced inflammation by secreting TGF- $\beta 3$ and TSP-1 to elicit macrophage M2 polarization. Cell Physiol Biochem 51: 2290-2308, 2018.

42. Kim YH, Kim YS, Kim BH, Lee KS, Park HS and Lim CH: Remote ischemic preconditioning ameliorates indirect acute lung injury by modulating phosphorylation of $\mathrm{I} \kappa \mathrm{B} \alpha$ in mice. J Int Med Res 47: 936-950, 2019.

43. Kany S, Vollrath JT and Relja B: Cytokines in inflammatory disease. Int J Mol Sci 20: 6008, 2019.

44. Lewis TC, Metitiri EE, Mentz GB, Ren X, Goldsmith AM, Eder BN, Wicklund KE, Walsh MP, Comstock AT, Ricci JM, et al: Impact of community respiratory viral infections in urban children with asthma. Ann Allergy Asthma Immunol 122: 175-183.e2, 2019

45. Butt Y,Kurdowska A and Allen TC: Acute lung injury: A clinical and molecular review. Arch Pathol Lab Med 140: 345-350, 2016.

46. Michaudel C, Couturier-Maillard A, Chenuet P, Maillet I, Mura C, Couillin I, Gombault A, Quesniaux VF, Huaux F and Ryffel B: Inflammasome, IL-1 and inflammation in ozone-induced lung injury. Am J Clin Exp Immunol 5: 33-40, 2016.

47. Garth J, Barnes JW and Krick S: Targeting cytokines as evolving treatment strategies in chronic inflammatory airway diseases. Int J Mol Sci 19: 3402, 2018.

48. Betakova T, Kostrabova A, Lachova V and Turianova L: Cytokines induced during influenza virus infection. Curr Pharm Des 23: 2616-2622, 2017

49. Hsieh YH, Deng JS, Chang YS and Huang GJ: Ginsenoside Rh2 ameliorates lipopolysaccharide-induced acute lung injury by regulating the TLR4/PI3K/Akt/mTOR, Raf-1/MEK/ERK, and Keap1/Nrf2/HO-1 signaling pathways in mice. Nutrients 10 : $1208,2018$.

50. Li J, Li D, Liu X, Tang S and Wei F: Human umbilical cord mesenchymal stem cells reduce systemic inflammation and attenuate LPS-induced acute lung injury in rats. J Inflamm (Lond) 9: 33, 2012.

This work is licensed under a Creative Commons Attribution-NonCommercial-NoDerivatives 4.0 International (CC BY-NC-ND 4.0) License. 